\title{
Bil2 Is a Novel Inhibitor of the Yeast Formin Bnr1 Required for Proper Actin Cable Organization and Polarized Secretion
}

\author{
Thomas J. Rands and Bruce L. Goode* \\ Department of Biology, Rosenstiel Basic Medical Sciences Research Center, Brandeis University, Waltham, MA, \\ United States
}

Cell growth in budding yeast depends on rapid and on-going assembly and turnover of polarized actin cables, which direct intracellular transport of post-Golgi vesicles to the bud tip. Saccharomyces cerevisiae actin cables are polymerized by two formins, Bni1 and Bnr1. Bni1 assembles cables in the bud, while Bnr1 is anchored to the bud neck and assembles cables that specifically extend filling the mother cell. Here, we report a formin regulatory role for YGL015c, a previously uncharacterized open reading frame, which we have named Bud6 Interacting Ligand 2 (BIL2). bil2 $\Delta$ cells display defects in

OPEN ACCESS

Edited by:

Ting Gang Chew,

Zhejiang University-University

of Edinburgh Institute, China

Reviewed by:

Naomi Courtemanche,

University of Minnesota Twin Cities, United States

Saravanan Palani,

Indian Institute of Science (IISC), India

*Correspondence:

Bruce L. Goode

goode@brandeis.edu

Specialty section:

This article was submitted to

Cell Growth and Division,

a section of the journal

Frontiers in Cell and Developmental

Biology

Received: 28 November 2020

Accepted: 20 January 2021

Published: 09 February 2021

Citation:

Rands TJ and Goode BL (2021)

Bil2 Is a Novel Inhibitor of the Yeast

Formin Bnr1 Required for Proper

Actin Cable Organization

and Polarized Secretion.

Front. Cell Dev. Biol. 9:634587.

doi: 10.3389/fcell.2021.634587 actin cable architecture and partially-impaired secretory vesicle transport. Bil2 inhibits Bnr1-mediated actin filament nucleation in vitro, yet has no effect on the rate of Bnr1mediated filament elongation. This activity profile for Bil2 resembles that of another yeast formin regulator, the F-BAR protein Hof1, and we find that bil2 $\Delta$ with hof1 $\Delta$ are synthetic lethal. Unlike Hof1, which localizes exclusively to the bud neck, GFP-Bil2 localizes to the cytosol, secretory vesicles, and sites of polarized cell growth. Further, we provide evidence that Hof1 and Bil2 inhibitory effects on Bnr1 are overcome by distinct mechanisms. Together, our results suggest that Bil2 and Hof1 perform distinct yet genetically complementary roles in inhibiting the actin nucleation activity of Bnr1 to control actin cable assembly and polarized secretion.

Keywords: actin, cable, formin, secretion, Bud6, Bni1, Bnr1, Bil2

\section{INTRODUCTION}

Formins are a conserved family of actin assembly-promoting proteins that perform essential roles in numerous actin-based cellular and physiological processes (Kovar, 2006; Chhabra and Higgs, 2007; Chesarone et al., 2010). Formins nucleate the assembly of new actin filaments and accelerate actin filament elongation while protecting growing barbed ends from capping proteins (Goode and Eck, 2007; Breitsprecher and Goode, 2013). Studies in yeast have led to important advances in our understanding of formin activities, mechanism, and regulation (Breitsprecher and Goode, 2013). Mammalian genomes encode 15 different formins (Higgs and Peterson, 2005), which are used to assemble a wide variety of cellular actin structures, including filopodia, stress fibers, stereocilia, and lamellipodia (Faix and Grosse, 2006). In contrast, the budding yeast Saccharomyces cerevisiae has just two formin genes, BNI1 and BNR1, and during most stages of the cell cycle they assemble only a single actin structure, the actin cable network. The relative simplicity of the yeast system, combined with its genetic tractability, have made it a powerful model for elucidating formin regulatory mechanisms. 
Bnil and Bnrl assemble actin cables from distinct locations in cells, the bud cortex and bud neck, respectively (Moseley and Goode, 2006). However, together they share one essential function in actin cable network assembly, which is crucial for secretory vesicle transport and polarized cell growth (Imamura et al., 1997; Evangelista et al., 2002; Sagot et al., 2002a; Gao and Bretscher, 2008). Bnil is transiently recruited from the cytosol to the bud cortex, where it assembles cables that fill the bud compartment and extend into the mother cell. In contrast, Bnr1 is stably anchored to the bud neck, where it assembles cables that specifically extend into the mother cell (Ozaki-Kuroda et al., 2001; Pruyne et al., 2004; Buttery et al., 2007, 2012; Gao et al., 2010). Actin cables extend toward the back of the mother cell at a rate of $\sim 0.3-0.7 \mu \mathrm{m} / \mathrm{sec}$, and are turned over at the same rate, which means that Bnil and Bnr1 continuously nucleating and elongating cables (Yang and Pon, 2002; Yu et al., 2011). Post-Golgi secretory vesicles are transported along the cables toward the bud tip by the essential myosin $\mathrm{V}$ protein (Myo2) (Govindan et al., 1995; Pruyne et al., 1998). It is believed that the dynamic and constant assembly of the actin cable networks enables them to be rapidly rearranged, and for cells to reorient polarized secretion and cell growth during different stages of the cell cycle (Bi and Park, 2012) and in response to external stimuli, e.g., during the mating response (Ghose and Lew, 2020) and wound healing (Kono et al., 2012). In addition, the rearward (or 'retrograde') treadmilling of the cables provides a quality control mechanism to help keep damaged organelles and proteins, accumulated during cellular aging, out of the bud and increase the fitness of daughter cells (Higuchi et al., 2013). However, these rapid dynamics also put a constant and high demand on the system for controlling actin cable extension rates and lengths. How this regulation is achieved it not fully understood, but appears to involve actin turnover-promoting factors such as cofilin and Aip1 (Okada et al., 2006) and formin-binding proteins that modulate formin actin assembly activity.

Factors that promote yeast formin-mediated actin assembly include profilin, Bud6, Bil1, and Aip5 (Evangelista et al., 1997; Moseley et al., 2004; Graziano et al., 2013; Glomb et al., 2019; Xie et al., 2019). Bud6 directly interacts with G-actin and the C-terminal tail regions of Bnil and Bnr1, positioning actin monomers near their actin-nucleating formin homology 2 (FH2) domains (Graziano et al., 2011). Interestingly, the Bud6-binding site (BBS) is positioned differently in Bnil compared to Bnr1, leading to a key difference in their regulation. The BBS on Bnil is adjacent to its C-terminal diaphanous autoregulatory domain (DAD), which is some distance from the $\mathrm{FH} 2$ domain (Moseley and Goode, 2005). As a result, Bud6 alone enhances Bnil-mediated actin nucleation. In contrast, the putative BBS on Bnr1 is much closer to its $\mathrm{FH} 2$ domain, and as a result, Bud6 alone obstructs actin nucleation by Bnrl (Graziano et al., 2013). However, addition of Bil1, a small Bud6-binding protein, unmasks Bud6's nucleation-promoting effects on Bnr1 (Graziano et al., 2013). Thus, Bill is required specifically for productive interactions of Bud6 with Bnr1, but not Bnil. In addition to factors that enhance nucleation, there are a number of yeast formin-binding partners that inhibit its nucleation and/or elongation activities, including Bud14, Smy1, and Hof1
(Chesarone et al., 2009; Chesarone-Cataldo et al., 2011; Graziano et al., 2013; Eskin et al., 2016; Garabedian et al., 2018). How these different stimulatory and inhibitory inputs work in concert to tune actin cable extension rate and length in vivo is only beginning to be understood.

All three known formin inhibitors in yeast (Hof1, Bud14, and Smy1) regulate Bnr1, but not Bni1. Whereas Bud14 and Smy1 inhibit Bnr1-mediated actin filament elongation (Chesarone et al., 2009; Chesarone-Cataldo et al., 2011; Eskin et al., 2016), Hof1 specifically inhibits Bnr1-mediated actin nucleation and has no effects on filament elongation (Graziano et al., 2014; Garabedian et al., 2018). Hof1 is stably anchored to the septin collar at the bud neck (Kamei et al., 1998; Vallen et al., 2000), similar to Bnr1, and deletion of HOF1 results in excessive actin assembly, leading to defects in cable orientation and vesicle transport (Graziano et al., 2014; Garabedian et al., 2018, 2020). Hof1 inhibition of Bnr1 is overcome by the nucleation-promoting factor (NPF) Bud6, which is delivered on secretory vesicles to the bud neck (Garabedian et al., 2018). This regulatory scheme of combining a stationary inhibitor (Hof1) with a mobile activator (Bud6) is thought to establish a positive feedback loop for promoting Bnrl-mediated actin cable nucleation. Biochemical experiments have elucidated parts of the underlying mechanism. A C-terminal fragment of Bud6 (489-788), called 'Bud6(L)', enhances Bnr1-mediated actin nucleation when accompanied by its in vivo binding partner Bud6 Interacting Ligand 1 (Bil1) (Graziano et al., 2013). These observations, supported by additional in vivo evidence, suggest that Bud6 and Bil1 work together to promote Bnr1-dependent actin cable nucleation.

In the present study, we identify YGL015c, a previously uncharacterized gene product, as a novel regulator of Bnrl activity and cellular function. YGL015c encodes a $15 \mathrm{kDa}$ protein, and in earlier proteomic studies was shown to interact with Bud6 and actin (Ito et al., 2001; Yu et al., 2008). This prompted us to investigate the potential role(s) of YGL015c in regulating formins and actin cable assembly. Based on its association with Bud6, and our own observations here of YGL015c co-localization with Bud6 on secretory vesicles, we named this gene Bud6 Interacting Ligand 2 (BIL2). Our biochemical and genetic results suggest that Bil2/YGL015c functions as a novel inhibitor of Bnr1-mediated actin nucleation, but not elongation, and that it shares an essential in vivo function with the formin regulator Hof1.

\section{MATERIALS AND METHODS}

\section{Plasmids and Yeast Strains}

A low-copy (CEN) plasmid was used to express GFP-SEC4 in S. cerevisiae (Calero et al., 2003). A CEN plasmid for expressing $\mathrm{GFP}^{\text {Envy }}$-SEC4 in S. cerevisiae was constructed by amplification of the GFP $\mathrm{Gnvy}^{\text {sny }}$ sequence from plasmid pFA6a-link-Envy-spHis5 (Slubowski et al., 2015) using primers (forward 5- CAT GCT GTC GAC ATG TCT AAA GGC GAG GAA TT-3; reverse 5- CAT TAG TCT AGA TTT GTA CAA TTC GTC CAT TC-3). The GFP $^{\text {Envy }}$ sequence was then stitched in frame with SEC4 using SalI and XbaI sites into the above-mentioned GFP-SEC4 plasmid. 
A GFP ${ }^{E n v y}$-BIL2 plasmid was constructed by PCR amplification of the YGL015c open reading frame using primers (forward 5CAT TAG TCT AGA ATG GAA GAC ACG ATA CGT CC-3; reverse 5- TAC GAT CCG CGG CTA ATC ATC AGA AGT GCA GC-3). This PCR product was cloned in frame with $\mathrm{GFP}^{\text {Envy }}$ using XbaI and SacII sites in the GFP Envy $-S E C 4$ plasmid above. Importantly, the sequence of the YGL015c open reading frame we amplified matched the sequence at the Saccharomyces Genome Database (SGD). A mCherry-SEC4 plasmid was constructed by PCR amplification of the mCherry sequence using primers (forward 5-TAG TCA GTC GAC ATG GTG AGC AAG GGC GAG GA-3; reverse 5- TGC TAC TCT AGA TTA CTT GTA CAG CTC GTC CA-3). This product was cloned in frame with SEC4, as above, using Sall and XbaI sites. The plasmids used for galactose-inducible expression in S. cerevisiae of $6 \mathrm{His}$-fusions of Bnr1 FH1-FH2-C (residues 757-1375) and Bnr1 FH2 (8681291) have been described (Moseley and Goode, 2005; Okada et al., 2010; Jaiswal et al., 2013). A plasmid used for Escherichia coli expression of full-length $6 \mathrm{His}-\mathrm{Bil} 2$ was constructed by PCR amplification of the $Y G L 015 c$ open reading frame using primers (forward 5-GAC TAG GGA TCC ATG GAA GAC ACG ATA CGT CC-3; reverse 5- TAG GAC AAG CTT CTA ATC ATC AGA AGT GCA GC-3). This PCR product was cloned in frame into the pET-28a vector using BamHI and HindIII sites. For expression of C-Bud6 in E. coli, the sequence encoding amino acids 489-788 of Bud6 was PCR amplified from genomic DNA and subcloned into pET-GST-TEV as previously described (Graziano et al., 2013).

All yeast strains used in this study are in the W303 background, with the exception of Figure 2E, which was in the ResGen background (see Supplementary Table 1). A bil2 $\Delta$ strain (BGY4248) was generated by integration of a selectable marker into the BIL2 locus as described (Longtine et al., 1998). To track secretory vesicles in live-imaging experiments, wildtype (BGY10) and bil2 $\Delta$ (BGY4248) cells were transformed with pGFP $^{\text {Envy }}$-SEC4. For analyzing Bnr1-GFP levels and neck localization, we crossed a Bnr1-GFP strain (BGY962) to a bil2 $\Delta$ strain (BGY4248). For genetic analyses, we crossed a bil2 $\Delta$ strain (BGY4248) to hof1 $\Delta$ (BGY4253), bud14 $\Delta$ (BGY4259), and bud6 $\Delta$ (BGY1249). To localizing Bud6 and Bil2 in vivo, we used a Bud6-mCherry strain (BGY3913) (Garabedian et al., 2018) transformed with $\mathrm{pGFP}^{\text {Envy }}$-BIL2. For biochemical isolation of secretory vesicles, we used two different strains, one with differential tags on Bud6 and Bil2, and one with differential tags on Bil2 and Sec4, generated as follows. We crossed a sec6-4 strain (a kind gift from Dr. Erfei Bi) to our BUD6-mCherry strain (BGY3913), producing BUD6-mCherry sec6-4 (BGY4258), which was then transformed with $\mathrm{pGFP}^{\text {Envy }}$-BIL2. We transformed the same sec6-4 strain with both $\mathrm{pGFP}^{\text {Envy }}$-BIL2 and mCherrySEC4 plasmids.

\section{Protein Purification}

Rabbit skeletal muscle actin was purified from acetone powder (Spudich and Watt, 1971) generated from frozen ground hind leg muscle tissue of young rabbits (Pel-Freez, United States). Lyophilized acetone powder stored at $-80^{\circ} \mathrm{C}$ was mechanically sheared in a coffee grinder, resuspended in G-buffer [ $5 \mathrm{mM}$ Tris$\mathrm{HCl} \mathrm{pH}$ 7.5, $0.5 \mathrm{mM}$ Dithiothreitol (DTT), $0.2 \mathrm{mM}$ ATP and $\left.0.1 \mathrm{mM} \mathrm{CaCl}_{2}\right]$, and then cleared by centrifugation for $20 \mathrm{~min}$ at $50,000 \times g$. Supernatant was collected and further filtered with Whatman paper. Actin was polymerized by addition of $2 \mathrm{mM}$ $\mathrm{MgCl}_{2}$ and $50 \mathrm{mM} \mathrm{NaCl}$ to the filtrate and overnight incubation at $4^{\circ} \mathrm{C}$ with slow stirring. The next morning, $\mathrm{NaCl}$ powder was added to a final concentration of $0.6 \mathrm{M}$, and the mixture was stirred for another $30 \mathrm{~min}$ at $4^{\circ} \mathrm{C}$. The F-actin was pelleted by centrifugation for $150 \mathrm{~min}$ at $120,000 \times \mathrm{g}$, and the pellet was solubilized by dounce homogenization and dialyzed against G-buffer for $48 \mathrm{~h}$ at $4^{\circ} \mathrm{C}$. Monomeric actin was then precleared by centrifugation at $435,000 \times g$, and loaded onto a S200 $(16 / 60)$ gel-filtration column (GE Healthcare, United States) equilibrated in G-Buffer. Peak fractions were stored at $4^{\circ} \mathrm{C}$.

To biotinylate actin on cysteine 374 , an F-actin pellet as above was dounced and dialyzed against G-buffer lacking DTT. Monomeric actin was then polymerized by addition of an equal volume of $2 \times$ labeling buffer (50 mM imidazole $\mathrm{pH}$ 7.5, $200 \mathrm{mM}$ $\mathrm{KCl}, 0.3 \mathrm{mM}$ ATP, and $4 \mathrm{mM} \mathrm{MgCl}_{2}$ ). After $5 \mathrm{~min}$, the actin was mixed with a fivefold molar excess of NHS-XX-Biotin (Merck $\mathrm{KGaA}$, Germany) and incubated in the dark for $15 \mathrm{~h}$ at $4^{\circ} \mathrm{C}$. The F-actin was pelleted as above, and the pellet was rinsed with G-buffer, then homogenized with a dounce, and dialyzed against G-buffer for $48 \mathrm{~h}$ at $4^{\circ} \mathrm{C}$. Biotinylated monomeric actin was purified further on an S200 (16/60) gel-filtration column as above. Aliquots of biotin-actin were snap frozen in liquid $\mathrm{N}_{2}$ and stored at $-80^{\circ} \mathrm{C}$.

To label actin with Oregon Green (OG) on cysteine 374, an F-actin pellet as above was dounced and dialyzed against G-buffer lacking DTT. Monomeric actin was then polymerized by addition of an equal volume of $2 \times$ labeling buffer. After $5 \mathrm{~min}$, the actin was mixed with a fivefold molar excess of OG-488 iodoacetamide (Invitrogen), resuspended in anhydrous dimethylformamide, and then incubated in the dark for $15 \mathrm{~h}$ at $4^{\circ} \mathrm{C}$. The labeled F-actin was pelleted as above, and the pellet was rinsed with G-buffer, depolymerized by Dounce homogenization, dialyzed against G-buffer for $60 \mathrm{~h}$ at $4^{\circ} \mathrm{C}$, and applied to an S200 $(16 / 60)$ gel filtration column. Peak fractions were dialyzed for $15 \mathrm{~h}$ against G-buffer with $50 \%$ glycerol and stored at $-20^{\circ} \mathrm{C}$.

To label actin with pyrenyl-iodoacetamide on cysteine 374 (Cooper et al., 1984; Graziano et al., 2013), an F-actin pellet prepared as above was dialyzed against pyrene buffer $(25 \mathrm{mM}$ Tris- $\mathrm{HCl}, \mathrm{pH}$ 7.5, $100 \mathrm{mM} \mathrm{KCl}, 0.3 \mathrm{mM}$ ATP, and $2 \mathrm{mM}$ $\mathrm{MgSO}_{4}$ ) for $4 \mathrm{~h}$ and then diluted with pyrene buffer to $1 \mathrm{mg} / \mathrm{mL}$ $(23.8 \mu \mathrm{M})$. A 10-fold molar excess of pyrenyl-iodoacetamide was added, and the actin solution was incubated overnight at $4^{\circ} \mathrm{C}$. The reaction was then centrifuged for $3 \mathrm{~h}$ at $4^{\circ} \mathrm{C} 150,000 \times g$ in a Ti60 rotor (Beckman Coulter, Indianapolis, IN, United States) to pellet the F-actin. F-actin pellets were dounced, and dialyzed against G-buffer for $48 \mathrm{~h}$ to depolymerize the actin, then loaded on a S200 (16/60) column equilibrated in G-buffer. Peak fractions were pooled, aliquoted, snap frozen in liquid $\mathrm{N}_{2}$, and stored at $-80^{\circ} \mathrm{C}$.

C-Bnr1 (FH1-FH2-C; 758-1375) and Bnr1-FH2 polypeptides (869-1,289) were expressed as $\mathrm{N}$-terminal 6His-fusions in S. cerevisiae strain BJ2168 from high copy plasmids under the control of a galactose-inducible promoter (Moseley and Goode, 2006). For each purification, 2 L of yeast cells were 
grown in synthetic medium lacking uracil with $2 \%$ raffinose to $\mathrm{OD}_{600}=0.6-0.9$. Then expression was induced by addition of dry ingredients: $10 \mathrm{~g}$ yeast extract, $20 \mathrm{~g}$ peptone, and galactose ( $2 \% \mathrm{wt} / \mathrm{vol}$ ). Cells were grown for $12-16 \mathrm{~h}$ at $30^{\circ} \mathrm{C}$, then pelleted, washed in $\mathrm{H}_{2} \mathrm{O}$, frozen dropwise in liquid $\mathrm{N}_{2}$, and stored at $-80^{\circ} \mathrm{C}$. To initiate a protein preparation, frozen yeast pellets were lysed mechanically in a coffee grinder cooled with liquid $\mathrm{N}_{2}$. Then, $20 \mathrm{~g}$ of lysed yeast powder was resuspended in $20 \mathrm{~mL}$ of buffer A $\left(20 \mathrm{mM} \mathrm{NaPO}_{4}, \mathrm{pH} 7.4,150 \mathrm{mM} \mathrm{NaCl}, 30 \mathrm{mM}\right.$ imidazole, $0.5 \mathrm{mM}$ DTT, $1 \%$ NP-40) supplemented with protease inhibitor cocktail as above, and cleared by ultracentrifugation at $200,000 \times g$ for $20 \mathrm{~min}$ in a TLA100.3 rotor (Beckman Coulter). Cleared lysates were then passed through a $0.45 \mu \mathrm{m}$ syringe filter (Millex, MilliporeSigma; Darmstadt, Germany) and the 6Histagged Bnrl polypeptides were incubated for $1 \mathrm{~h}$ at $4^{\circ} \mathrm{C}$ with $2 \mathrm{~mL}$ of Ni-NTA beads (New England Biolabs; Ipswich, MA, United States) with gentle agitation. Beads were washed three times with $10 \mathrm{~mL}$ wash buffer $(20 \mathrm{mM}$ Tris $\mathrm{pH} 8.0,500 \mathrm{mM} \mathrm{NaCl}$, $0.5 \mathrm{mM}$ DTT, and $30 \mathrm{mM}$ Imidazole), and Bnr1 polypeptides were eluted with $4 \mathrm{~mL}$ of elution buffer (20 mM Tris $\mathrm{pH} 8.0$, $500 \mathrm{mM} \mathrm{NaCl}, 0.5 \mathrm{mM}$ DTT, and $300 \mathrm{mM}$ Imidazole). Peak fractions were pooled and loaded on a PD10 desalting column (GE Life Sciences; Marlborough, MA, United States) equilibrated with HEKG $_{10}$ D buffer (20 mM HEPES, pH 7.5, 1 mM EDTA, $50 \mathrm{mM} \mathrm{KCl}, 10 \%$ [vol/vol] glycerol, and $1 \mathrm{mM} \mathrm{DTT})$, then concentrated to $\sim 200 \mu \mathrm{L}$, aliquoted, snap frozen in liquid $\mathrm{N}_{2}$, and stored at $-80^{\circ} \mathrm{C}$.

S. cerevisiae profilin was expressed in BL21(DE3) E. coli and purified as described (Graziano et al., 2013). Bacterial cells were grown in terrific broth to log phase and induced with $0.4 \mathrm{mM}$ IPTG for $3-4 \mathrm{~h}$ at $37^{\circ} \mathrm{C}$. Cells were pelleted and stored at $-80^{\circ} \mathrm{C}$. Frozen pellets were thawed, resuspended in lysis buffer (20 mM Tris- $\mathrm{HCl}, \mathrm{pH} 8.0)$ supplemented with a protease inhibitor cocktail ( $1 \mathrm{mM}$ PMSF, $0.5 \mu \mathrm{M}$ each of pepstatin A, antipain, leupeptin, aprotinin, and chymostatin), and lysed by incubation with lysozyme and sonication. Lysates were cleared by centrifugation at $200,000 \times g$ at $4^{\circ} \mathrm{C}$ for $20 \mathrm{~min}$ in a TLA100.3 rotor (Beckman Coulter). The supernatant was then loaded on a $5 \mathrm{ml}$ HiTrap Q fast flow column (GE Healthcare), and profilin was eluted using a $75 \mathrm{~mL}$ salt gradient $(0-400 \mathrm{mM}$ $\mathrm{NaCl}$ ) in $20 \mathrm{mM}$ Tris-HCl, pH 8.0. Peak fractions were pooled, concentrated to $5 \mathrm{~mL}$, and loaded on a Superdex (26/60) gel filtration column (GE Healthcare) equilibrated in G-buffer. Peak fractions were pooled, aliquoted, snap frozen in liquid $\mathrm{N}_{2}$, and stored at $-80^{\circ} \mathrm{C}$.

6 His-Bil2 protein was expressed in Rosetta 2 BL21(DE3) E. coli cells carrying a plasmid for expression of rare codons (MilliporeSigma; Darmstadt, Germany). Cells were grown to $\mathrm{OD}_{600}=0.7-0.9$ in terrific broth supplemented with kanamycin and chloramphenicol to maintain selection of the expression plasmid and the pRARE plasmid, respectively. Expression was induced with $0.4 \mathrm{mM}$ IPTG overnight at $18^{\circ} \mathrm{C}$, and then cells were pelleted and stored at $-80^{\circ} \mathrm{C}$. To initiate a preparation, a cell pellet was thawed, resuspended in lysis buffer $(20 \mathrm{mM}$ Tris $\mathrm{pH}$ 8.0, $500 \mathrm{mM} \mathrm{NaCl}, 0.5 \mathrm{mM}$ DTT, and $30 \mathrm{mM}$ Imidazole) with the same protease inhibitor cocktail as above, and lysed by treatment with $1 \mathrm{mg} / \mathrm{mL}$ lysozyme, $0.1 \mathrm{mg} / \mathrm{mL}$ DNAse I, and sonication.
Lysates were cleared by centrifugation at $10,000 \times g$ for $20 \mathrm{~min}$ in an F21S-8 $\times$ 50y rotor (Thermo Fisher Scientific; Waltham, MA, United States), and the supernatant was mixed with $1 \mathrm{~mL}$ of Ni-NTA beads (New England Biolabs) and rotated at $4^{\circ} \mathrm{C}$ for $1 \mathrm{~h}$. The beads were then washed 3 times with $10 \mathrm{ml}$ wash buffer (20 mM Tris pH 8.0, $500 \mathrm{mM} \mathrm{NaCl}, 0.5 \mathrm{mM}$ DTT, and $30 \mathrm{mM}$ Imidazole) in a gravity column at $4^{\circ} \mathrm{C}$. $6 \mathrm{His}$-Bil2 was eluted from the beads using elution buffer $(20 \mathrm{mM}$ Tris pH 8.0, $500 \mathrm{mM} \mathrm{NaCl}$, $0.5 \mathrm{mM}$ DTT, and $300 \mathrm{mM}$ Imidazole), exchanged into $\mathrm{HEKG}_{10} \mathrm{D}$ on a PD10 desalting column (GE Life Sciences), concentrated to $\sim 200 \mu \mathrm{L}$, aliquoted, snap frozen in liquid $\mathrm{N}_{2}$ and stored at $-80^{\circ} \mathrm{C}$.

Bud6(L) was expressed in BL21(DE3) E. coli and purified as previously described (Graziano et al., 2011). Bacterial cells were grown in terrific broth to late log phase and induced using $0.4 \mathrm{mM}$ IPTG for $3-4 \mathrm{~h}$ at $37^{\circ} \mathrm{C}$. Cells were pelleted and frozen at $-80^{\circ} \mathrm{C}$. Frozen pellets were thawed, resuspended in lysis buffer (50 mM Tris, pH 8.5, $150 \mathrm{mM} \mathrm{NaCl,} 5 \mathrm{mM}$ EDTA, $1.5 \%$ sarkosyl, $5 \mathrm{mM}$ DTT, and standard protease inhibitors), treated with lysozyme, and sonicated. Cell lysates were cleared by centrifugation at $12,000 \mathrm{rpm}$ for $10 \mathrm{~min}$ in a Sorvall S600 rotor (Thermo Fisher Scientific). Triton X-100 (final concentration $3.3 \%[\mathrm{vol} / \mathrm{vol}]$ ) was added to the supernatant, and the mixture was mixed with $1 \mathrm{ml}$ of preswollen glutathione agarose in PBS (137 mM NaCl, $2.7 \mathrm{mM} \mathrm{KCl,} 4.3 \mathrm{mM} \mathrm{Na} 2 \mathrm{HPO} 4$, and $1.47 \mathrm{mM}$ $\mathrm{KH} 2 \mathrm{PO} 4, \mathrm{pH} 7.4$ ). After incubation at $4^{\circ} \mathrm{C}$ for $3-4 \mathrm{~h}$, beads were washed four times with PBS, and then twice with HEKD (20 mM Hepes, pH 7.5, $1 \mathrm{mM}$ EDTA, $50 \mathrm{mM} \mathrm{KCl}$, and $1 \mathrm{mM}$ DTT). Bud6(L) was cleaved from GST and released from beads by digestion with TEV protease for $2 \mathrm{~h}$ at room temperature and snap frozen.

\section{Fixed Cell Imaging}

To analyze actin cable organization in cells, yeast were grown to $\mathrm{OD}_{600}=0.4-0.6$ in YEPD media, fixed in 5\% formaldehyde for $45 \mathrm{~min}$ at room temperature, and then washed three times with PBS buffer. Cells were stained 1-3 days with Alexa Fluor 488 phalloidin (Life Technologies; Grand Island, NY, United States), and then washed three times with PBS buffer. For experiments in which actin cables were analyzed using SOAX, an open source program for biopolymer networks (Xu et al., 2015), cells were treated with $100 \mu \mathrm{M}$ CK666 (Sigma-Aldrich; St. Louis, MO, United States) for $20 \mathrm{~min}$ before fixation to inhibit the Arp2/3 complex and remove cortical actin patches. Fixed and stained cells then were imaged by structured illumination microscopy (SIM) on a Nikon Ti-2 SIM-E inverted microscope with a Hamamatsu Orca Flash 4.0 camera controlled by NIS-Elements software (Nikon Instruments), using an exposure time of $200 \mathrm{~ms}$ at $488 \mathrm{~nm}$ excitation and $40 \%$ laser power. From the SIM images, individual cells were cropped and background was subtracted, then actin cables were analyzed using SOAX. To optimize detection of cables in the SOAX analysis, default settings were used, with two exceptions: R-threshold value was set to 0.008 , and $\mathrm{k}$-stretch factor was set to 0.5 . This automated analysis quantifies number of cable segments in cells.

For coefficient of variation (CoV) analysis of cable distribution, samples of the cell preparations made above 
(fixed and phalloidin stained) were imaged by SIM, using the same settings as above. CoV measurements are made by first tracing the outline of the mother cell compartment in ImageJ, and then measuring the mean fluorescence of actin cable staining and the standard deviation. The $\mathrm{CoV}$ is a ratio of the standard deviation over the mean. Wildtype cells typically have brightly stained cables against a dark background, yielding a high standard deviation, and therefore a higher CoV. Mutants with disorganized and dispersed actin cable networks have lower stand deviation values and consequently lower CoVs.

\section{Live Cell Imaging}

For imaging secretory vesicle traffic, wildtype and mutant yeast strains were transformed with a CEN plasmid expressing $\mathrm{GFP}^{\text {Envy }}$-Sec4. Cells were grown at $25^{\circ} \mathrm{C}$ to $\mathrm{OD}_{600}=0.4-0.8$ in synthetic selective media, then mounted on slides and imaged on an i-E upright confocal microscope (Nikon Instruments) with a CSU-W1 spinning disk head (Yokogawa), $100 \times$ oil objective (NA 1.4; Nikon Instruments), and an Ixon 897 UltraCCD camera (Andor Technology) controlled by NIS-Elements software (Nikon Instruments). Exposure times of $50 \mathrm{~ms}$ at $50 \%$ intensity (excitation $488 \mathrm{~nm}$ ) were used to image cells for $2 \mathrm{~min}$. Movies were analyzed in ImageJ as follows. Secretory vesicle movements were monitored within the mother cells $(n>25)$ of each strain by manually tracking the positions over time for 38 puncta $\left(\mathrm{GFP}^{\text {Envy }}\right.$-Sec4) per cell. Tortuosity measurements were made by dividing the length of the path (from the initial point of movement to the bud neck) by the distance between the point of origin and the bud neck. In addition, for each strain, we calculated the fraction of $\mathrm{GFP}^{E n v y}$-Sec4 puncta in the mother cell that were successfully transported to the bud during a $30 \mathrm{~s}$ observation window ( $n>20$ cells per condition).

To compare Bnr1-GFP (endogenously tagged) levels at the bud neck of wildtype and bil $2 \Delta$ cells, yeast were grown at $25^{\circ} \mathrm{C}$ in synthetic media to $\mathrm{OD}_{600}=0.4-0.8$, then mounted on slides, and immediately imaged on an i-E upright confocal microscope (Nikon Instruments) with a CSU-W1 spinning disk head (Yokogawa), 100× oil objective (NA 1.4; Nikon Instruments), and an Ixon 897 Ultra-CCD camera (Andor Technology) controlled by NIS-Elements software (Nikon Instruments). Each image was acquired using an exposure time of $100 \mathrm{~ms}$ at $488 \mathrm{~nm}$ excitation with $20 \%$ laser power. Z-stacks (15 images) were obtained by capturing images every $0.2 \mu \mathrm{m}$, and were analyzed in ImageJ as follows; $Z$-stacks were combined using the "sum projection" function, then a box of fixed dimensions was drawn to encompass the bud neck and measure the Bnrl-GFP integrated fluorescence density.

For the Pearson's correlation analysis of Bud6-mCherry and $\mathrm{GFP}^{\text {Envy }}$-Bil2 colocalization, yeast cells were grown in synthetic selective media to mid-log phase, mounted on slides, and immediately imaged as above. Images were acquired using exposure times of $200 \mathrm{~ms}$ for Bud6-mCherry (561 nm excitation; $40 \%$ laser power) and $500 \mathrm{~ms}$ for $\mathrm{GFP}^{\text {Envy }}$-Bil2 (488 nm excitation; $80 \%$ laser power). Individual cells from the images were cropped, background was subtracted, and colocalization was analyzed using the Coloc2 plugin in ImageJ.
To quantify the ratio of GFP-Sec4 signal in the bud versus the entire cell, yeast transformed with the low copy GFP-Sec4 plasmid were grown in synthetic selective media to mid-log phase, mounted on slides, and immediately imaged as above. Images were acquired using exposure times of $50 \mathrm{~ms}(488 \mathrm{~nm}$ excitation; $40 \%$ laser power). Integrated density values were determined by selecting the bud and the whole cell using the ROI tool in ImageJ. The ratio of the signal in these two compartments was calculated by dividing the amount of signal in the bud by the amount of signal in the whole cell.

\section{Secretory Vesicle Isolation}

Secretory vesicles were isolated from yeast cells using methods adapted from those previously described (Harsay and Bretscher, 1995). Cells were grown at $25^{\circ} \mathrm{C}$ to $\mathrm{OD}_{600}=0.7$ in $1 \mathrm{~L}$ cultures of selective media, then shifted to $37^{\circ} \mathrm{C}$ for $2 \mathrm{~h}$. Cells were then harvested by centrifugation for $20 \mathrm{~min}$ at $3,000 \times g$, washed with ice-cold $10 \mathrm{mM} \mathrm{NaN}_{3}$, and incubated for $15 \mathrm{~min}$ on ice in softening buffer [0.1 M Tris- $\mathrm{H}_{2} \mathrm{SO}_{4}$ (pH 9.4), $50 \mathrm{mM} \mathrm{1,3-}$ mercaptoethanol, and $10 \mathrm{mM} \mathrm{NaN}_{3}$ ]. Next, cells were washed in ice-cold spheroplast wash buffer (1.4 M sorbitol, $50 \mathrm{mM}$ $\mathrm{KPi}, \mathrm{pH} 7.5$, and $10 \mathrm{mM} \mathrm{NaN}_{3}$ ), resuspended in the same buffer supplemented with $0.15 \mathrm{mg} / \mathrm{mL}$ Zymolyase-100T (US Biological; Salem, MA, United States), and incubated at $37^{\circ} \mathrm{C}$ for $2 \mathrm{~h}$ with gentle agitation. Spheroplasted cells were harvested by gentle centrifugation at $2,000 \times g$, and then gently washed two times with ice-cold spheroplast wash buffer (no zymolase), resting the samples on ice for $10 \mathrm{~min}$ between each wash to allow pellets to loosen. Next, using a plastic transfer pipette, the pellets were gently resuspended (to minimize lysis) in $30 \mathrm{~mL}$ of lysis buffer $(0.8 \mathrm{M}$ sorbitol, $10 \mathrm{mM}$ triethanolamine, $1 \mathrm{mM}$ EDTA, adjusted to $\mathrm{pH} 7.2$ using acetic acid, $1 \mathrm{mM}$ PMSF, and $0.5 \mu \mathrm{M}$ each of pepstatin $\mathrm{A}$, antipain, leupeptin, aprotinin, and chymostatin). The spheroplasts were transferred to a tight-fitting glass Dounce homogenizer, lysed with 20 strokes of the pestle, and then centrifuged at $700 \times g$ for $10 \mathrm{~min}$, generating the P1 (pellet) and S1 (supernatant) fractions. Then, the S1 fraction was centrifuged at $13,000 \times g$ for 20 min to generate the P2 fraction (containing large organelles) and the S2 fraction (containing secretory vesicles and soluble proteins). The S2 fraction was then centrifuged for $1 \mathrm{~h}$ at $100,000 \times g$ to generate the P3 fraction (secretory vesicles) and S3 fraction (soluble proteins). The P3 fraction was resuspended in lysis buffer and mounted on slides, and imaged on an i-E upright confocal microscope (Nikon Instruments) with a CSU-W1 spinning disk head (Yokogawa), $100 \times$ oil objective (NA 1.4; Nikon Instruments), and an Ixon 897 Ultra-CCD camera (Andor Technology) controlled by NISElements software (Nikon Instruments). Images were acquired using exposure times of $200 \mathrm{~ms}$ for GFP-Bil2 (488 nm excitation; $50 \%$ laser power) and $100 \mathrm{~ms}$ for mCherry-Sec4 and Bud6mCherry (561 nm excitation; 50\% laser power).

\section{Pyrene-Actin Assembly Assays}

Gel-filtered monomeric actin (5\% pyrene-labeled) in G-buffer (5 mM Tris- $\mathrm{HCl} \mathrm{pH} \mathrm{8.0,} 0.2 \mathrm{mM}$ ATP, $0.2 \mathrm{mM} \mathrm{CaCl}$, and $0.2 \mathrm{mM}$ DTT) was converted to $\mathrm{Mg}$-ATP-actin immediately before each reaction (Moseley and Goode, 2005). Final reactions 
were $60 \mu \mathrm{L}$ containing $2 \mu \mathrm{M}$ G-actin. To initiate a reaction, $42 \mu \mathrm{L}$ of the ATP-G-actin stock was mixed with $15 \mu \mathrm{L}$ of proteins and/or control $\mathrm{HEKG}_{5}$ buffer, then mixed with $3 \mu \mathrm{L}$ of $20 \times$ initiation mix (40 $\mathrm{mM} \mathrm{MgCl}_{2}, 10 \mathrm{mM} \mathrm{ATP}$, and $1 \mathrm{M} \mathrm{KCl}$ ) to initiate polymerization. Fluorescence was monitored at excitation $365 \mathrm{~nm}$ and emission $407 \mathrm{~nm}$ at $25^{\circ} \mathrm{C}$ in a fluorimeter (Photon Technology International, Lawrenceville, NJ, United States).

\section{Total Internal Reflection Fluorescence (TIRF) Microscopy}

Glass coverslips $(60 \mathrm{~mm} \times 3 \mathrm{~mm} \times 24 \mathrm{~mm}$; Thermo Fisher Scientific) were cleaned by sonication for $30 \mathrm{~min}$ in detergent, followed by $1 \mathrm{M} \mathrm{KOH}$, and $1 \mathrm{M} \mathrm{HCl}$, and then stored in $100 \%$ ethanol. Coverslips were coated with a mixture of $4 \mathrm{mg} / \mathrm{mL}$ polyethylene glycol (PEG)-silane and $80 \mathrm{mg} / \mathrm{mL}$ biotin-PEG in $80 \%$ ethanol $\mathrm{pH} 1.0$, then washed with water and dried with compressed N2. PEG-coated coverslips were stored for 13 days at $70^{\circ} \mathrm{C}$ prior to use. Flow chambers were constructed by sandwiching glass coverslips on top of plastic flow chambers (Ibidi, Fitchburg, WI, United States) using double-sided tape $(2.5 \mathrm{~cm} 3 \mathrm{~mm} \times 2 \mathrm{~mm} \times 3 \mathrm{~mm} \times 120 \mathrm{~mm})$ and 5-min epoxy resin (Devcon, Riviera Beach, FL, United States). To anchor actin filaments in TIRF reactions, $4 \mathrm{mg} / \mathrm{mL}$ streptavidin in HEK buffer (20 mM HEPES pH 7.4, $1 \mathrm{mM}$ EDTA, and $50 \mathrm{mM} \mathrm{KCl}$ ) was flowed into the TIRF chamber for $15 \mathrm{~s}$ using a syringe pump (Harvard Apparatus, Holliston, MA, United States). Then the chamber was washed with HEK buffer $+1 \%$ BSA. The chamber was then equilibrated with TIRF buffer [10 mM HEPES pH 7.4, $50 \mathrm{mM} \mathrm{KCl}, 1 \mathrm{mM} \mathrm{MgCl} 2,1 \mathrm{mM}$ EGTA, $0.2 \mathrm{mM}$ ATP, $10 \mathrm{mM}$ DTT, $15 \mathrm{mM}$ glucose, $20 \mathrm{mg} / \mathrm{mL}$ catalase, $100 \mathrm{mg} / \mathrm{mL}$ glucose oxidase, $10 \mathrm{mM}$ Imidazole, and $0.5 \%$ methylcellulose $(4000 \mathrm{cP})]$. Prior to experiments, the proteins used in TIRF reactions [His6Bil2, Bud6(L), C-Bnr1, profilin, and Bnr1-FH2] were diluted into TIRF buffer. A fixed volume of proteins (different combinations) was rapidly mixed with a final concentration of $1 \mu \mathrm{M}$ G-actin (10\% OG-labeled, $0.2 \%$ biotinylated, as indicated) and flowed into the TIRF chamber. The TIRF chamber was then immediately mounted on the microscope for imaging. The delay between mixing proteins and initial imaging was $60 \mathrm{~s}$. Time-lapse TIRF imaging was performed on a Ti200 inverted microscope (Nikon Instruments, New York, NY, United States) equipped with $100 \mathrm{~mW}$ solid-state lasers (Agilent Technologies, Santa Clara, CA, United States), a CFI Apo $60 \times 1.49$ N.A. oil-immersion TIRF objective (Nikon Instruments), a iXon EMCCD camera with a pixel size of $0.267 \mathrm{~mm}$ (Andor Technology), and an additional $1.5 \times$ zoom module (Nikon Instruments). Focus was maintained using the Perfect Focus System (Nikon Instruments), and frames were captured every $10 \mathrm{~s}$ for a total of $600 \mathrm{~s}(10 \mathrm{~ms}$ at $488 \mathrm{~nm}$ excitation, 15\% laser power) using NIS Elements software (Nikon Instruments). Image analysis was performed in FIJI, where background fluorescence was removed from each time series using the background subtraction tool in Fiji (rolling ball radius, 50 pixels). For measuring the number of actin filaments nucleated in TIRF reactions, fields of view were analyzed $200 \mathrm{~s}$ after the initiation of TIRF imaging. For each TIRF reaction, four separate fields of view were monitored and analyzed. To measure elongation rates, filament lengths were measured at different time points (using the freehand line tool in ImageJ). This analysis was limited to filaments that could be tracked for at least $60 \mathrm{~s}$ without growing out of the field of view. To measure filament elongation rates, plots of filament length versus time were generated, and the rates of elongation were determined from the slopes of the lines. To express rates in actin subunits $\mathrm{s}^{-1}$, we used the conversion factor of 374 subunits per $\mu \mathrm{m}$ length of F-actin (Huxley and Brown, 1967).

\section{RESULTS}

\section{Bil2 Is Required for Proper Transport of Post-Golgi Secretory Vesicles From the Mother Cell to the Bud}

There are no known defects in cell growth or morphology caused by a deletion of YGL015c (henceforth referred to as BIL2), and we confirmed this here. However, a genome-wide study reported that bil2 $\Delta$ cells abnormally accumulate a cargo protein in the trans-Golgi, suggesting a defect late in the secretory pathway (Proszynski et al., 2005). We considered the possibility that this defect might arise from altered actin organization, given that post-Golgi vesicles are transported on actin cables to the bud. Therefore, we used live imaging to compare the spatial distribution and movements of secretory vesicles (marked with GFP-Sec4) in wildtype and bil2 $\Delta$ cells (Figure 1A). Overall, vesicles were polarized to the bud to a similar degree in wildtype and bil2 $\Delta$ cells (Supplementary Figures 1A,B). However, our analysis of vesicle movements revealed differences in bil $2 \Delta$ cells. To analyze the vesicle movements, we traced their paths of transport over time (example traces in Figure 1B), and then quantified path lengths and tortuosity (ratio of path length to distance traveled). Vesicle paths in bil2 $\Delta$ cells were not significantly longer compared to wildtype cells (Figure 1C), but changed direction more often, making them circuitous (Figure 1D). We also assessed the overall efficiency of vesicle traffic, by quantifying the fraction of vesicles in mother cells that successfully translocated to the bud compartment during a $30 \mathrm{~s}$ window, and observed a modest yet significant decrease in transport efficiency in bil2 $\Delta$ cells (Figure 1E). Together, these observations show that bil $2 \Delta$ cells are partially defective in transporting post-Golgi vesicles to the bud, which may explain the previously observed cargo buildup in the trans-Golgi of bil2 $\Delta$ cells (Proszynski et al., 2005).

\section{Loss of BIL2 Leads to Disorganized Actin Cable Networks Assembled by Bnr1}

Previously, we showed that mutants in smy1 and hof1 that have defective actin cable organization also show altered vesicle path lengths and tortuosity (Eskin et al., 2016; Garabedian et al., 2018). Therefore, the circuitous nature of the vesicle paths in bil2 $\Delta$ cells prompted us to carefully compare cable organization between wildtype and bil2 $\Delta$ cells using superresolution structured illumination microscopy (SIM). Loss of BIL2 led to a visible disorganization of cable networks, with 
A
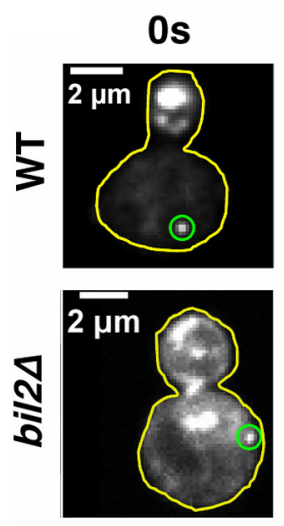

\section{GFP-Sec4}
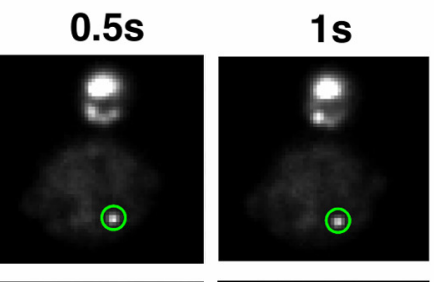

$1.5 \mathrm{~s}$

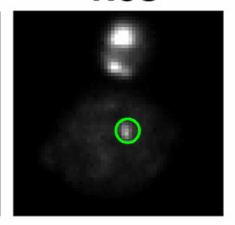

$2 s$

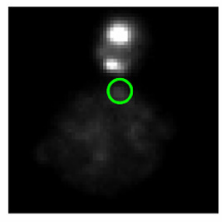

$2.5 \mathrm{~s}$
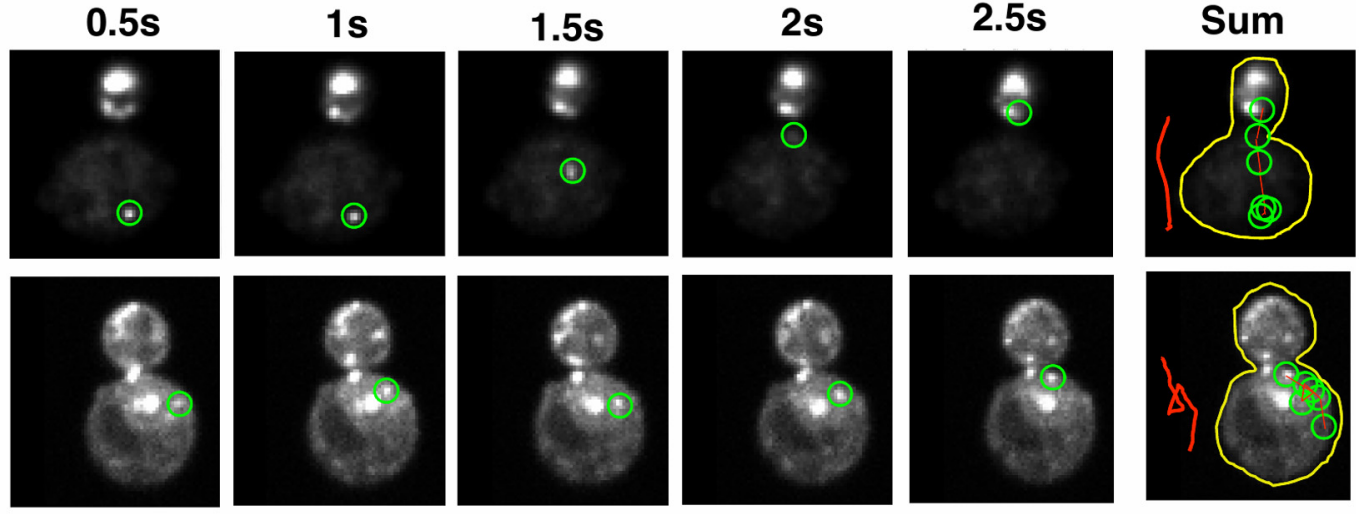

B
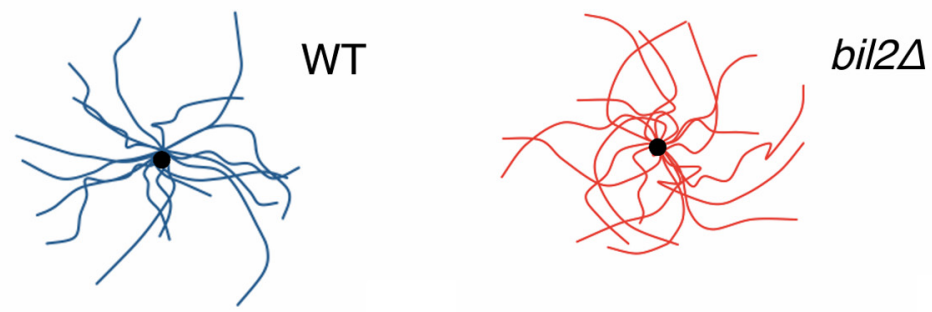

c

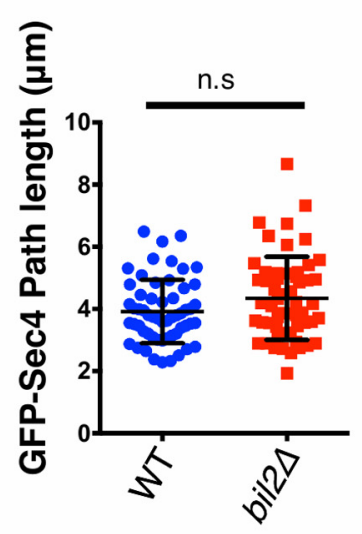

D

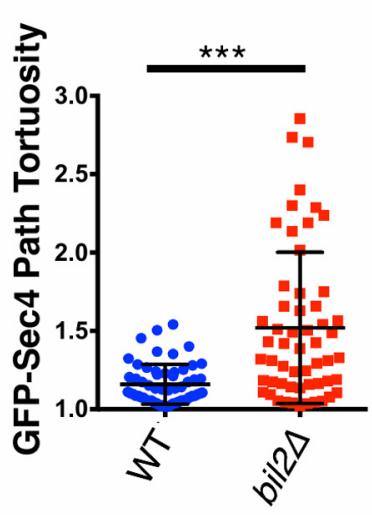

E

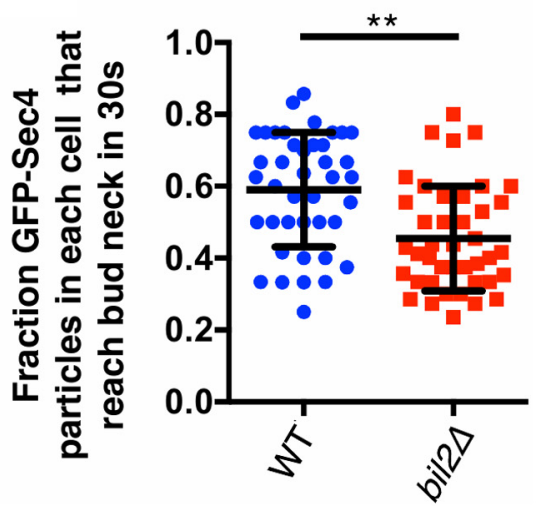

FIGURE 1 | BIL2 is required for efficient polarized delivery of secretory vesicles. (A) Representative time-lapse images showing the transport path of a secretory vesicle (GFPEnvy -Sec4) moving from the mother to the bud. At each time point shown, the vesicle being tracked is highlighted by a green circle. To the right is a sum of vesicle positions over time, with a line (red) marking the transport path. The sum of the transport paths are isolated and expanded on the right. (B) Bouquets of representative transport paths for secretory vesicles (15 each) in wildtype and bil $2 \Delta$ cells. Vesicle traces are organized such that they start at the periphery of the bouquets and terminate at the central dot (corresponding to the bud neck). (C) Quantification of GFPEnvy -Sec4 path lengths from traces as in (B) ( $n=25$ vesicles per experiment, 2 independent experiments. Number of cells: experiment 1: 17 for each strain; experiment 2: 18 for each strain). (D) Tortuosity of transport paths (ratio of path length to distance traveled) for the same vesicles in (C). (E) Fraction of vesicles successfully transported from the mother compartment to the bud during a 30 s observation window ( $n=20$ cells per condition per experiment, 2 independent experiments). Each dot represents the fraction of vesicles successfully transported to the bud in one cell. In all panels, bars show mean and SD. Statistical significance calculated by 2-way student $T$-test in all panels (n.s., no significance, ${ }^{*} p \leq 0.05,{ }^{* \star} p \leq 0.01,{ }^{* \star *} p \leq 0.001$ ).

minimal effect on polarized distribution of cortical actin patches (Figure 2A). To analyze actin cable organization defects in a more quantitative and unbiased manner, we also employed an open source program (SOAX), which skeletalizes the cable networks from cell images (Xu et al., 2015). Cells were pretreated with the Arp2/3 complex inhibitor CK666 to remove actin patches before this analysis to provide a less obstructed view of the cable networks and increase the accuracy of the SOAX analysis (Figure 2B). We focused our analysis on the cable networks in the mother cells, and found that bil2 $\Delta$ cells have an increased number of cable segments compared to wildtype cells (Figure 2C). Additionally, we performed coefficient of variation $(\mathrm{CoV})$ analysis on the same mother cells, measuring the mean fluorescence of cable staining and dividing by the standard 
deviation of the fluorescence (Figure 2D). Since wildtype cells have a well-defined and brightly stained set of actin cables against a dark background, they have a relatively high standard deviation, and a higher $\mathrm{CoV}$. In contrast, mutants with disorganized cable networks, e.g., hof1 $\Delta$ cells (Garabedian et al., 2020), have a lower standard deviation, and a lower CoV. Our data show that bil $2 \Delta$ cells have a lower $\mathrm{CoV}$ compared to wildtype cells, which agrees with our SOAX analysis, and together these results indicate that Bil2 is required for the formation of properly organized actin cable networks.

We next asked whether BIL2 contributes to the organization of actin cables assembled by Bnil and/or Bnr1, which grow from the bud tip and bud neck, respectively. A comparison of cable organization in bni1 $\Delta$ and bni1 $\Delta$ bil $2 \Delta$ cells, and in bnr $1 \Delta$ and bnr $1 \Delta$ bil $2 \Delta$ revealed that the loss of BIL2 significantly impaired actin cable organization in the bnil $\Delta$ background, but no the bnr1 $\Delta$ background. These results suggest that BIL2 functions to regulate $B N R 1$-nediated actin assembly to govern proper cable organization in the mother cell (Figures 2C,D). Further, the loss of BIL2 showed no effect on Bnr1-GFP levels at the bud neck (Figure 2E), indicating that Bil2 does not influence cable architecture by changing Bnr1 protein levels or localization.

\section{Bil2 Inhibits Bnr1-Mediated Actin Nucleation in vitro}

Our in vivo observations above inspired us to test in vitro whether Bil2 has any effects on Bnr1-mediated actin assembly activity. To address this, we purified $6 \mathrm{His}-\mathrm{Bil} 2$ from E. coli and first tested its effects in bulk actin assembly assays. As expected, C-Bnr1 (FH1-FH2-C) rapidly nucleated actin polymerization (Figure 3A), and was enhanced by its nucleation-promoting factors Bud6(L) and Bill (Graziano et al., 2013). The addition of Bil2 strongly inhibited C-Bnr1 effects, both in the presence and absence of Bud6(L), but had no effect on the assembly of actin alone in the absence of C-Bnr1. Interestingly, however, the further addition of Bill to reactions containing Bil2, Bud6(L), and $\mathrm{C}$-Bnr1 led to rapid actin assembly. On the other hand, Bil1 failed to release C-Bnr1 from Bil2 inhibition in the absence of Bud6(L) (Supplementary Figure 2). Thus, Bill and Bud6(L) together are required to overcome Bil2 inhibition of C-Bnrl.

To gain additional insights into Bil2 inhibitory effects on C-Bnr1, we used TIRF microscopy assays, and directly visualized individual actin filaments being assembled in real time, where we could distinguish effects on nucleation from effects on filament elongation. In these assays, C-Bnrl alone increased the number of new filaments formed compared to control reactions, and Bil2 inhibited the nucleation effects (Figures 3B,C). To assess whether Bil2 also affects the rate of filament elongation, we pre-assembled filaments in the presence or absence of C-Bnr1, and then flowed in Bil2 or control buffer, and monitored change in filament length over time. As expected, C-Bnr1 markedly increased the rate of filament elongation in the presence of profilin (ChesaroneCataldo et al., 2011). Flowing in Bil2 did not significantly alter the rate of filament elongation by C-Bnr1 (Figure 3D), suggesting that Bil2 acts on C-Bnrl primarily to inhibit actin nucleation and not elongation.
To better understand how Bil2 blocks Bnr1-mediated actin nucleation, we asked whether it can inhibit an FH2 domain-only (Bnr1-FH2) construct. These nucleation assays were performed in the absence of profilin, since FH2 domains (without FH1 domains) nucleate actin assembly only in the absence of profilin (Sagot et al., 2002b). Bil2 strongly inhibited Bnr1-FH2 nucleation activity (Figure $3 \mathrm{E}$ ), suggesting that it may interact with the $\mathrm{FH} 2$ domain to block nucleation.

Finally, in our TIRF experiments, we noticed that all Bil2containing reactions had a number of small puncta (marked by labeled actin), regardless of whether or not those reactions contained C-Bnr1 (Figure 3B). Therefore, we asked whether the puncta were comprised of F-actin or G-actin by pre-incubating reactions with Latrunculin $B$ to block actin polymerization (Coué et al., 1987). While Latrunculin B blocked actin filament formation, as expected, it did not block formation of the actin puncta induced by the presence of Bil2 (Figure 3F). These observations suggest that Bil2 may bind to actin monomers, consistent with its reported two-hybrid interaction with actin (Yu et al., 2008).

\section{BIL2 and HOF1 Genetically Interact and Share an Essential in vivo Function}

The activity profile of Bil2, as an inhibitor of Bnr1-mediated actin nucleation without affecting elongation, is similar to only one other known yeast formin regulator, Hof1. This prompted us test genetic interactions between BIL2 and HOF1. We therefore crossed bil $2 \Delta$ and hof $1 \Delta$ haploid strains, and as controls crossed bil $2 \Delta$ to mutants in two other yeast formin regulators, bud6 $\Delta$ and bud14 $\Delta$. The resulting diploids were sporulated, tetrads were dissected, and haploid progeny were assessed for growth. This analysis revealed that the majority of bil $2 \Delta$ hof $1 \Delta$ double mutants were inviable, as compared to control crosses where the majority of double mutants were viable (Figure 4A). These observations demonstrate that BIL2 and HOF1 share an essential function in vivo. To gain additional insights into this function, we analyzed the viable bil $2 \Delta$ hof $1 \Delta$ double mutants. Compared to single mutants, the viable double mutants were severely compromised for cell growth (Figure 4B) and had enlarged cell sizes (Figure 4C) and disorganized actin cable networks (Figures 4C,D). Together, these in vivo observations suggest that Bil2 and Hof1 may perform related, complementary roles in controlling Bnrl-mediated actin cable nucleation and polarized cell growth.

\section{Bil2 Localizes to Polarity Sites and Associates With Secretory Vesicles}

To gain additional insights into Bil2 in vivo function, we investigated the localization of Bil2 endogenously tagged at its C-terminus with GFP or 3GFP. Unfortunately, we could not detect the expression of endogenously tagged Bil2-GFP or Bil2-3GFP. It is not clear whether Bil2 expression is very low to begin with, or the $\mathrm{C}$-terminal tags reduced the level of expression. However, we were able to detect $\mathrm{N}$-terminally tagged GFP-Bil2 expressed from a low copy plasmid under the control of the strong constitutive ACT1 promoter (Figure 5A). 

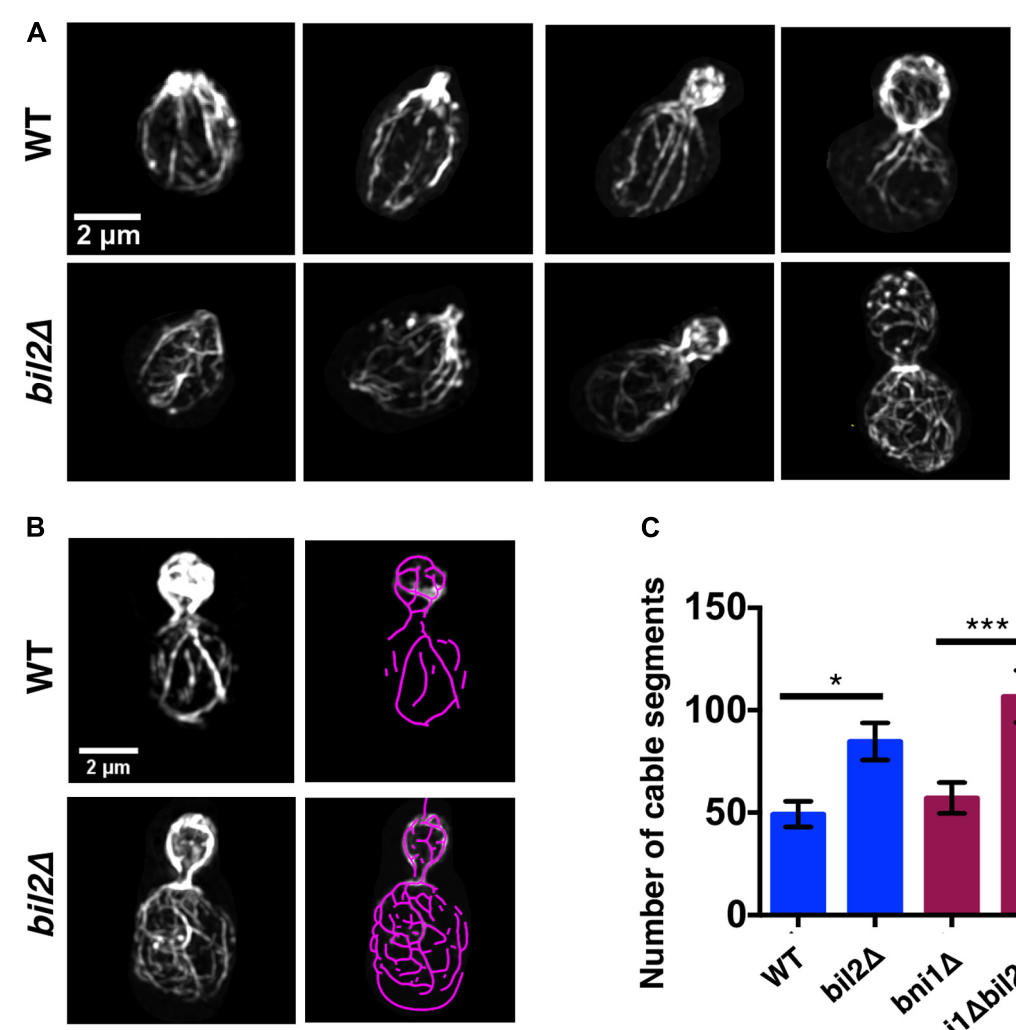

C
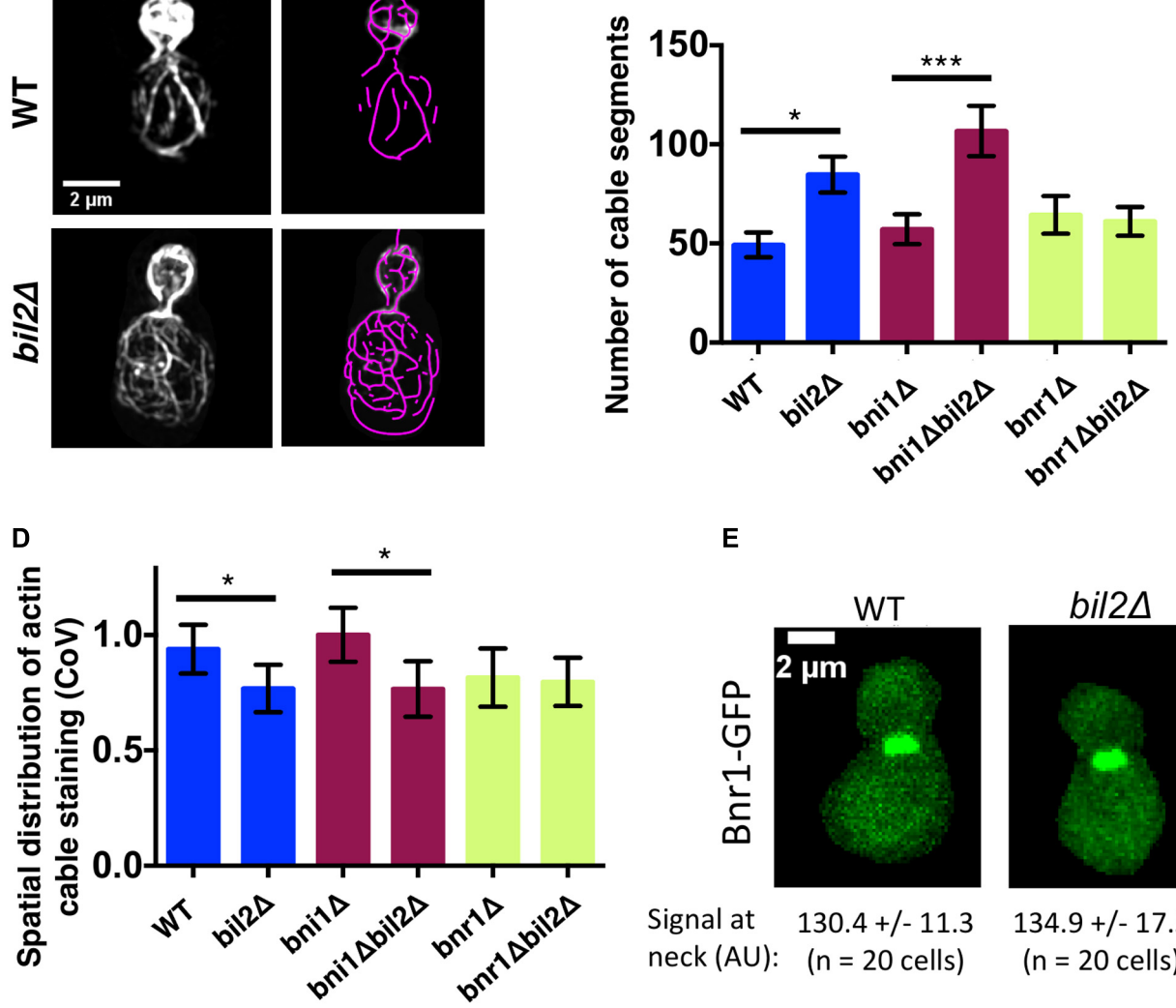

E
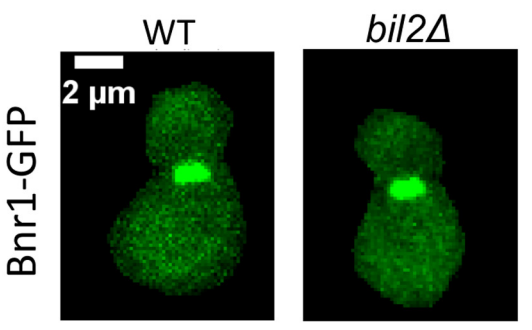

Signal at $\quad 130.4+/-11.3 \quad 134.9+/-17.5$

neck (AU): $\quad(n=20$ cells $) \quad(n=20$ cells $)$

FIGURE 2 | Loss of BIL2 disrupts the spatial organization of Bnr1-polymerized actin cable networks. (A) Representative structured illumination microscopy (SIM) images of F-actin organization in CK666 treated, phalloidin stained wildtype and bil2 $\Delta$ cells at different stages of bud growth. (B) Automated traces of actin cables from SIM images as in (A), created using SOAX. Left, phalloidin stained cell. Right, purple cable segments generated by SOAX. (C) Average number of actin cable segments per cell analyzed by SOAX ( $n=20$ cells per condition from two independent experiments). (D) Coefficient of variation (CoV) of phalloidin staining within the mother compartment of cells treated with CK666 ( $n=20$ cells per condition from two independent experiments). (E) Representative images of endogenously-expressed Bnr1-GFP in wildtype (WT) and bil2 $\Delta$ cells, with quantification of signals at the bud neck (mean and SD) below each image. In all panels, statistical significance calculated by 2 -way student $T$-test (n.s., no significance, ${ }^{*} p \leq 0.05,{ }^{\star \star} p \leq 0.01,{ }^{\star \star *} p \leq 0.001$ ).

Importantly, this plasmid complemented bil2 $\Delta$ defects in secretory vesicle transport (Figure 5B), suggesting that although the protein is likely to be expressed at higher levels than endogenous Bil2, it is nonetheless capable of performing Bil2's normal functions. GFP-Bil2 localized to the cytosol, to the bud neck and bud tip (sites of polarized growth), and to faint mobile puncta (suggestive of secretory vesicles). However, we acknowledge that addition of the GFP tag and/or the overexpression of Bil2 may alter its normal localization pattern. Interestingly, Bud6-GFP localizes to similar sites, although it shows more pronounced localization to polarity sites and secretory vesicles compared to Bil2 (Jin and Amberg, 2000; Segal et al., 2000). Deletion of BUD6 did not noticeably change GFP-Bil2 localization (Supplementary Figure 3A), 

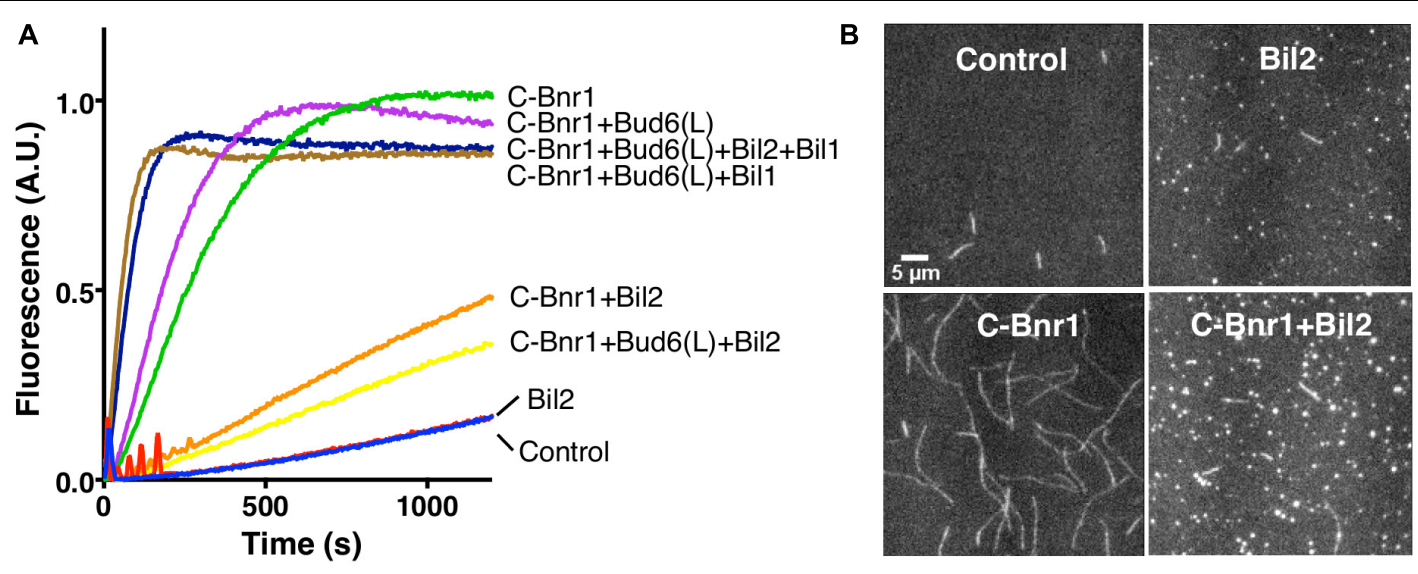

C

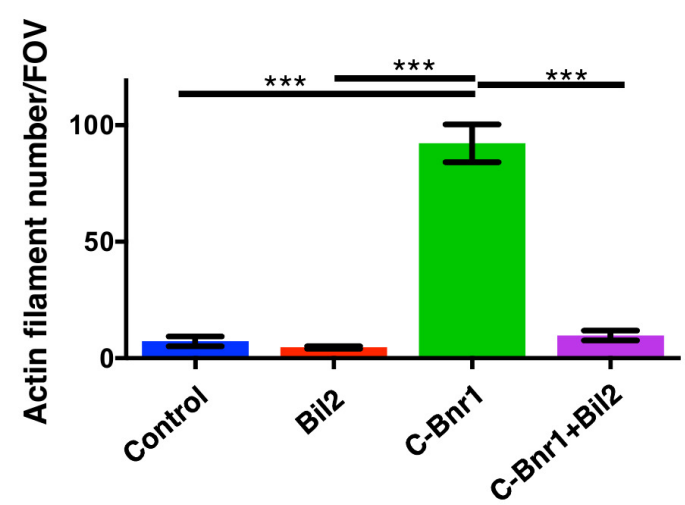

E

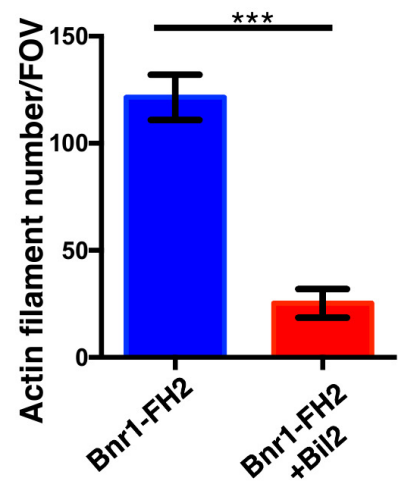

D

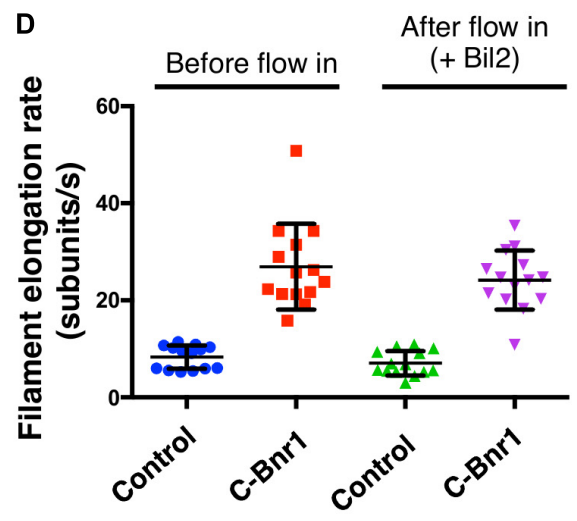

FIGURE 3 | Purified Bil2 inhibits Bnr1-mediated actin nucleation but not elongation. (A) Bulk pyrene-actin assembly assays showing that Bil2 inhibits Bnr1-dependent actin nucleation, both in the presence and absence of Bud6. Bil2 with Bud6 and Bil1 present did not inhibit Bnr1. Reactions contain $2 \mu \mathrm{M}$ actin monomers (5\% pyrene labeled) and $5 \mu \mathrm{M}$ profilin, with 2 nM C-Bnr1 (FH1-FH2-C; 758-1,375), 100 nM Bud6(L) (489-788), 100 nM Bil1, and/or 100 nM Bil2, as indicated. (B) Representative images from TIRF microscopy experiments showing the effects of Bil2 on Bnr1-mediated actin assembly. Reactions contain $1 \mu \mathrm{M}$ actin monomers (10\% Oregon green labeled) and $3 \mu \mathrm{M}$ profilin, with $0.1 \mathrm{nM}$ C-Bnr1 and/or $100 \mathrm{nM}$ Bil2, as indicated. Images shown are from $200 \mathrm{~s}$ after the initiation of actin assembly. (C) Quantification of the number of actin filaments nucleated per field of view (FOV) at $200 \mathrm{~s}$ into TIRF reactions as in (B) (four FOVs per condition). Shown are the mean and SEMs. (D) Quantification of filament elongation rates for TIRF reactions as in (B), except that $100 \mathrm{nM}$ Bil2 was flowed into reactions 5 min after initiation of actin assembly ( $n=20$ filaments per condition). (E) Bil2 inhibits Bnr1 (FH2)-mediated actin filament assembly. Quantification of number of filaments nucleated per field of view (FOV) at $200 \mathrm{~s}$ into TIRF reactions as in B (four FOVs per condition). Reactions contain $1 \mu \mathrm{M}$ actin monomers (10\% Oregon green labeled) and $0.1 \mathrm{nM} \mathrm{Bnr1} \mathrm{(FH2),} \mathrm{with} \mathrm{and} \mathrm{without} 100 \mathrm{nM}$ Bil2. (F) TIRF fields showing that Bil2 produces latrunculin-resistant actin puncta. Reactions contain $1 \mu \mathrm{M}$ actin monomers (10\% Oregon green labeled), $3 \mu \mathrm{M}$ profilin, and $100 \mathrm{nM}$ Bil2, with or without $100 \mathrm{nM}$ Latrunculin B. Images shown are from $200 \mathrm{~s}$ after the initiation of actin assembly. Shown are the mean and SEMs. Statistical significance calculated by 2 -way student $T$-test in all panels (n.s., no significance, ${ }^{*} p \leq 0.05,{ }^{\star \star} p \leq 0.01$, $\left.{ }^{* * *} p \leq 0.001\right)$. 
A

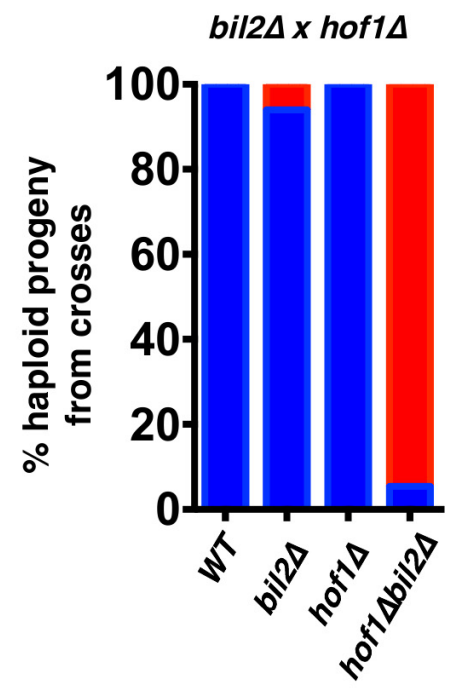

B

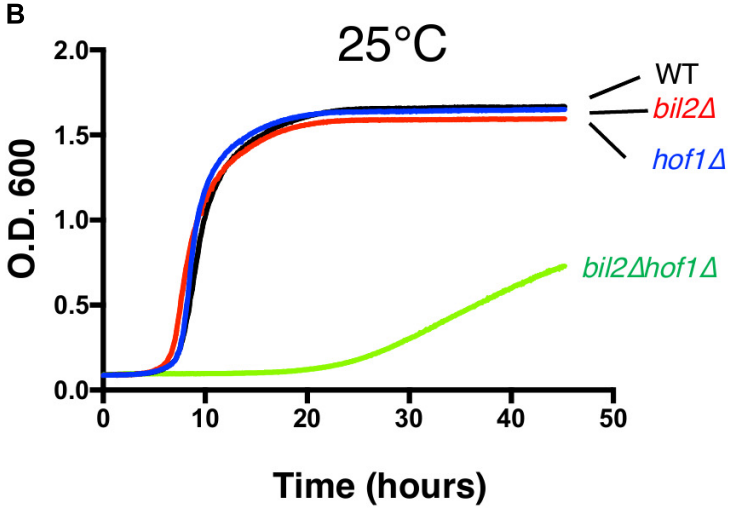

D

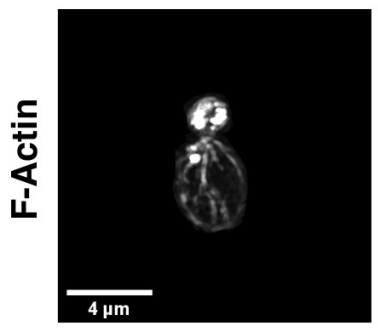

WT

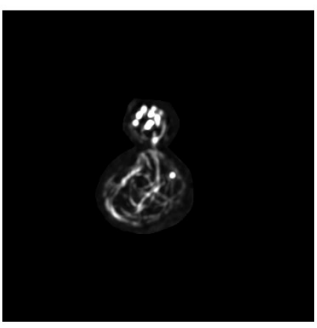

bil24

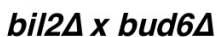

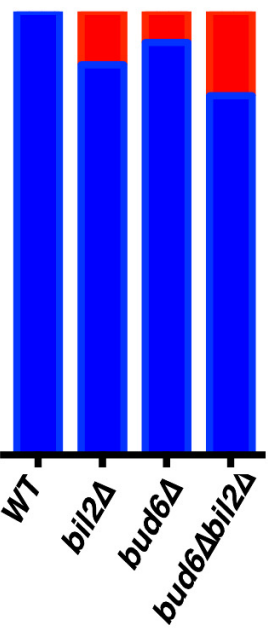

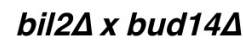

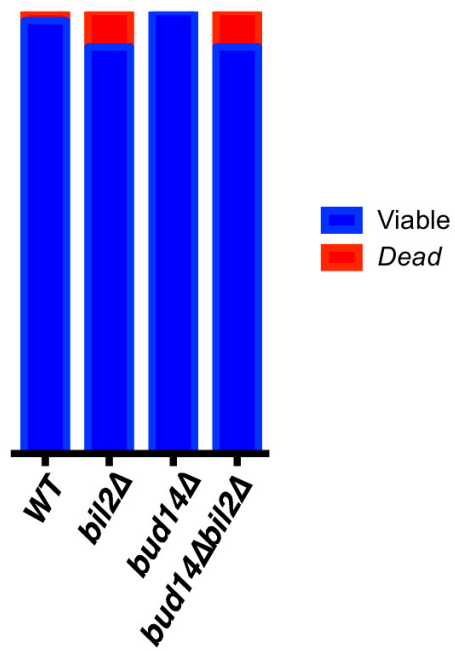

C

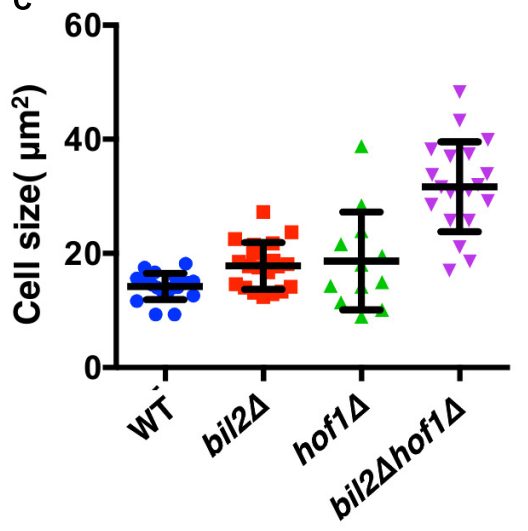

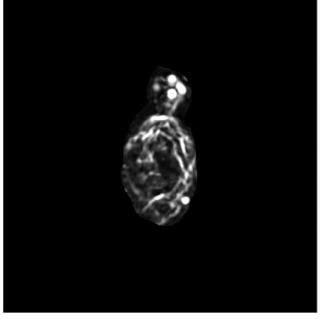

hof1 $\Delta$

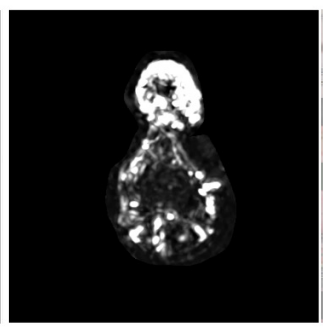

bil2 1 hof1 $\Delta$

FIGURE 4 | Synthetic genetic interactions between BIL2 and HOF1. (A) bil2 $\Delta$ haploids were crossed to haploids carrying deletions in other Bnr1 regulatory genes, including HOF1, BUD6, and BUD14. Diploids were sporulated, and tetrads dissected and genotyped ( $n=144,64$, and 104 tetrads from crosses with hof1 $\Delta$, bud6 $\Delta$, and bud $14 \Delta$, respectively). Resulting wildtype, single mutant, and double mutant haploids were analyzed for viability at $25^{\circ} \mathrm{C}$. (B) The indicated haploid strains were compared for growth in synthetic complete media at $25^{\circ} \mathrm{C}$ in a shaking microplate reader for $50 \mathrm{~h}$, monitoring growth (OD 600$)$ every 5 min. Lines represent the average of three independent cultures per strain. (C) Cell size was determined from DIC images in ImageJ by outlining each cell and calculating its area ( $n=20$ cells per condition). Shown are the mean and SD. (D) Representative max projection Z-stacks of phalloidin stained cells imaged by structured illumination microscopy (SIM). Note cell size is to scale, i.e., hof1 $\Delta$ bil2 $\Delta$ cells are enlarged compared to wildtype, hof1 $\Delta$, and bil2 $\Delta$ cells, as indicated in (C).

and deletion of BIL2 did not noticeably change Bud6-GFP localization (Supplementary Figure 3B). Thus, despite their ability to interact, Bud6 and Bil2 appear to localize independently to polarity sites.
Localization of GFP-Bil2 in live cells overlapped significantly with Bud6-mCherry and with mCherry-Sec4 (Figure 5C). Bud6 has been localized to secretory vesicles (Garabedian et al., 2018), which have a similar appearance to the faint mobile puncta we 
A
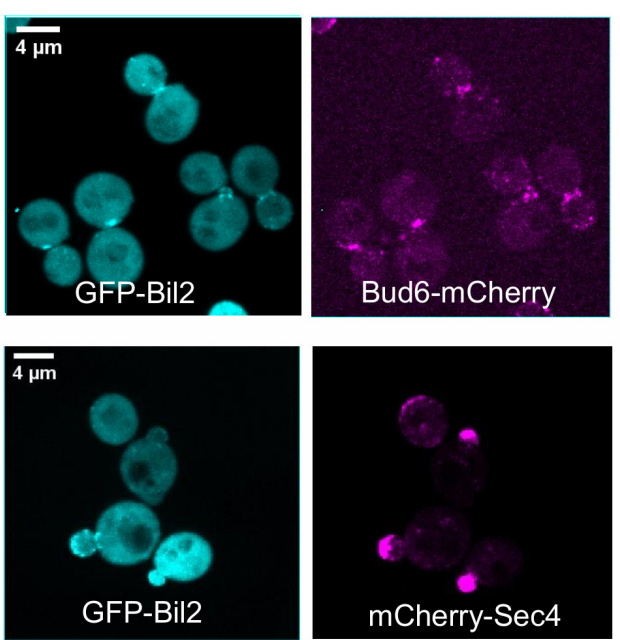

B

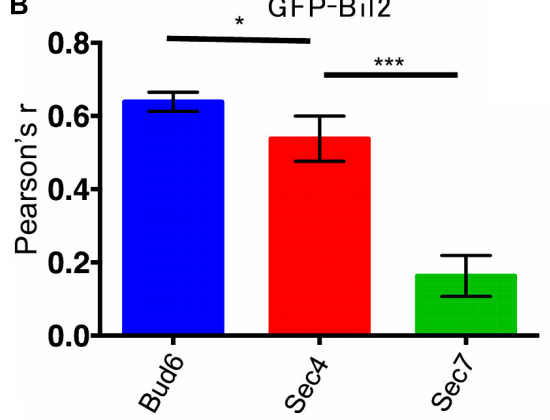

C

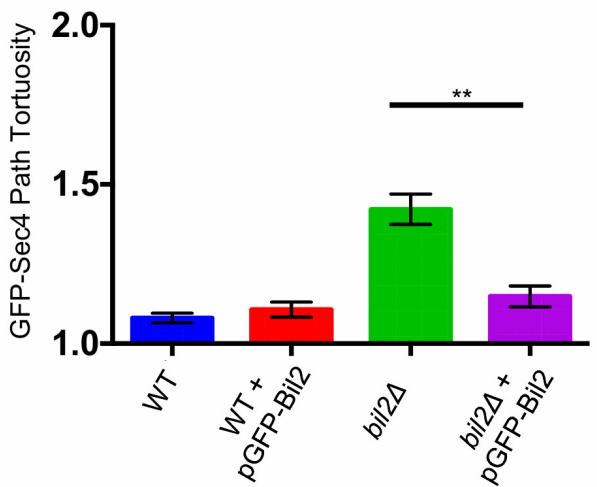

D Isolated secretory vesicles
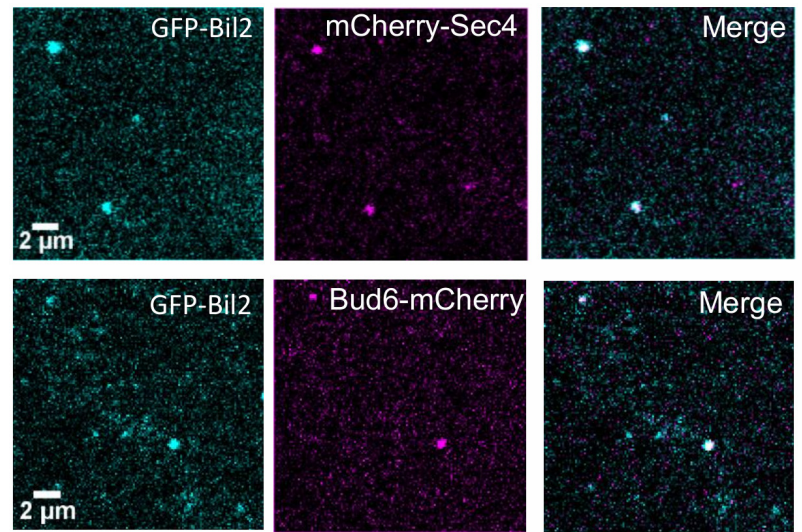
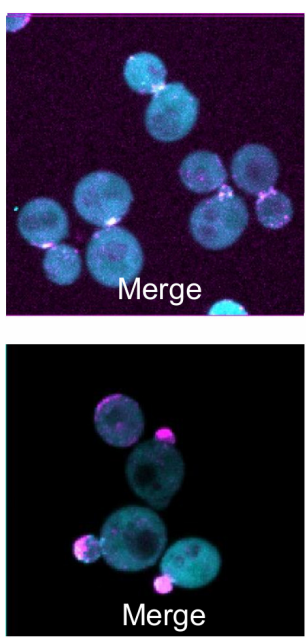

FIGURE 5 | GFP-Bil2 localization to polarity sites and association with secretory vesicles. (A) Representative images of live cells expressing GFP-Bil2 (from a low copy plasmid under the control of the ACT1 promoter) and either integrated Bud6-mCherry or mCherry-Sec4 (expressed from a low copy plasmid under the control of its own promoter). (B) GFP-Bil2 colocalization in live cells with mCherry-Sec4 (secretory vesicle marker) or Sec7-mCherry (trans-Golgi marker) quantified by Pearson correlation. (C) Comparison of GFP-Sec4 vesicle transport paths (ratio of path length to distance traveled) in wildtype (WT) and bil2 $\Delta$ cells with or without the pACT1-GFP-Bil2 plasmid ( $n=25$ vesicles per condition). (D) Representative fields of view of secretory vesicles isolated from cells expressing GFP-Bil2 (plasmid, as in A) along with Bud6-mCherry (integrated) or mCherry-Sec4 (plasmid, as in A). (E) Quantification of GFP-Bil2 colocalization with Bud6- and Sec4-positive secretory vesicles. Statistical significance in all panels calculated by 2 -way student $T$-test (n.s., no significance, ${ }^{\star} p \leq 0.05,{ }^{* \star} p \leq 0.01,{ }^{\star \star \star} p \leq 0.001$ ).

observed for GFP-Bil2. To further test the association of Bil2 with secretory vesicles, we performed a biochemical fractionation. Differential centrifugation was used to isolate secretory vesicles from cells co-expressing GFP-Bil2 with either Bud6-mCherry or mCherry-Sec4, and then colocalization was assessed by microscopy (Figure 5D). The majority of GFP-Bil2 puncta 
( $\sim 80 \%)$ colocalized with mCherry-Sec4, and approximately half of the GFP-Bil2 puncta colocalized with Bud6-mCherry (Figure 5E). These results more conclusively demonstrate that Bil2 associates with secretory vesicles, and suggest that approximately half of the Bil2-positive vesicles also harbor Bud6.

\section{DISCUSSION}

The initial goal of this study was to explore the cellular functions of a previously uncharacterized gene, YGL015c (BIL2), which was reported to interact with actin and the formin nucleationpromoting factor Bud6 (Ito et al., 2001; Yu et al., 2008). A previous proteomic screen had also identified this gene as being required for normal delivery of a marker protein to the cell surface via the secretory pathway, revealing that in bil2 $\Delta$ cells the surface protein aberrantly accumulated in the trans-Golgi compartment (Proszynski et al., 2005). However, the specific role(s) of BIL2 in this pathway were unclear. Given its suggested interactions with Bud6, which promotes formin-mediated actin cable nucleation, we decided to explore the possibility that Bil2 regulates formin-mediated actin cable assembly. Our in vivo observations showed that bil2 $\Delta$ cells have defects in Bnr1dependent actin cable architecture, including an increase in the total number of cable segments and a disorganization or entanglement of cable networks in mother cells. Consistent with these defects, the transport paths of secretory vesicles in bil2 $\Delta$ cells were more circuitous compared to the paths of vesicles in wildtype cells. Further, purified Bil2 inhibited Bnr1-mediated actin nucleation but not filament elongation in vitro, both in bulk and TIRF microscopy assays. Based on these genetic and biochemical observations, we propose that Bil2 functions, at least in part, as a novel inhibitor of Bnr1-mediated actin cable nucleation required for proper secretory traffic.

Although a number of direct regulators of Bnrl activity have been identified to date, the only other one with an activity profile similar to Bil2 is the F-BAR protein Hof1. Like Bil2, Hofl inhibits Bnr1-mediated actin nucleation but not filament elongation (Graziano et al., 2014). In addition, both Bil2 and Hof1 inhibit the actin-nucleating FH2 domain of Bnr1. A lowresolution EM structure of the Hof1-FH2 complex revealed that the F-BAR domain of Hof1 binds to the FH2 domain near its actin-binding surfaces (Garabedian et al., 2018). It is possible that Bil2 uses a related mechanism to inhibit Bnr1. Alternatively, a Bil2-actin complex might directly interact with the Bnr1 FH2 domain to block nucleation. Indeed, it was recently shown that the mammalian formin INF2 is inhibited by binding of a cyclase-associated protein (CAP)-actin complex (Mu et al., 2019). Consistent with their related biochemical activities in suppressing Bnr1-mediated actin nucleation, we found that bil2 $\Delta$ and hof $1 \Delta$ mutations are synthetic lethal. These results suggest that Bil2 and Hof1 have overlapping, possibly complementary roles in controlling formin-mediated actin cable assembly in vivo. Nearly all of the bil2 $\Delta$ hof $1 \Delta$ double mutants were lethal, possibly due to a lethal level of disrupted secretory traffic and impaired polarized growth. The small percentage of bil $2 \Delta$ hof $1 \Delta$ double mutant cells that were viable grew very slowly and had enlarged cell morphologies.

Our observations raise the question of why yeast cells have so many different inhibitors for one formin (Bnr1). Bil2 and Hof1 inhibit Bnr1-mediated actin nucleation and genetically interact. Bud14 and Smy1 inhibit actin filament nucleation and elongation by Bnr1 and genetically interact (Chesarone et al., 2009; Chesarone-Cataldo et al., 2011). None of these four inhibitors of Bnr1 have any direct effects on Bnil activity. Thus, cells appear to require tight spatiotemporal control over Bnr1 activity (nucleation and elongation) in order to build proper cable networks consisting of the appropriate number of cables with the appropriate length and architecture for optimal secretory traffic. It is also worth noting that no inhibitors of Bnil activity have been identified to date. This may be related to Bnr1 having a

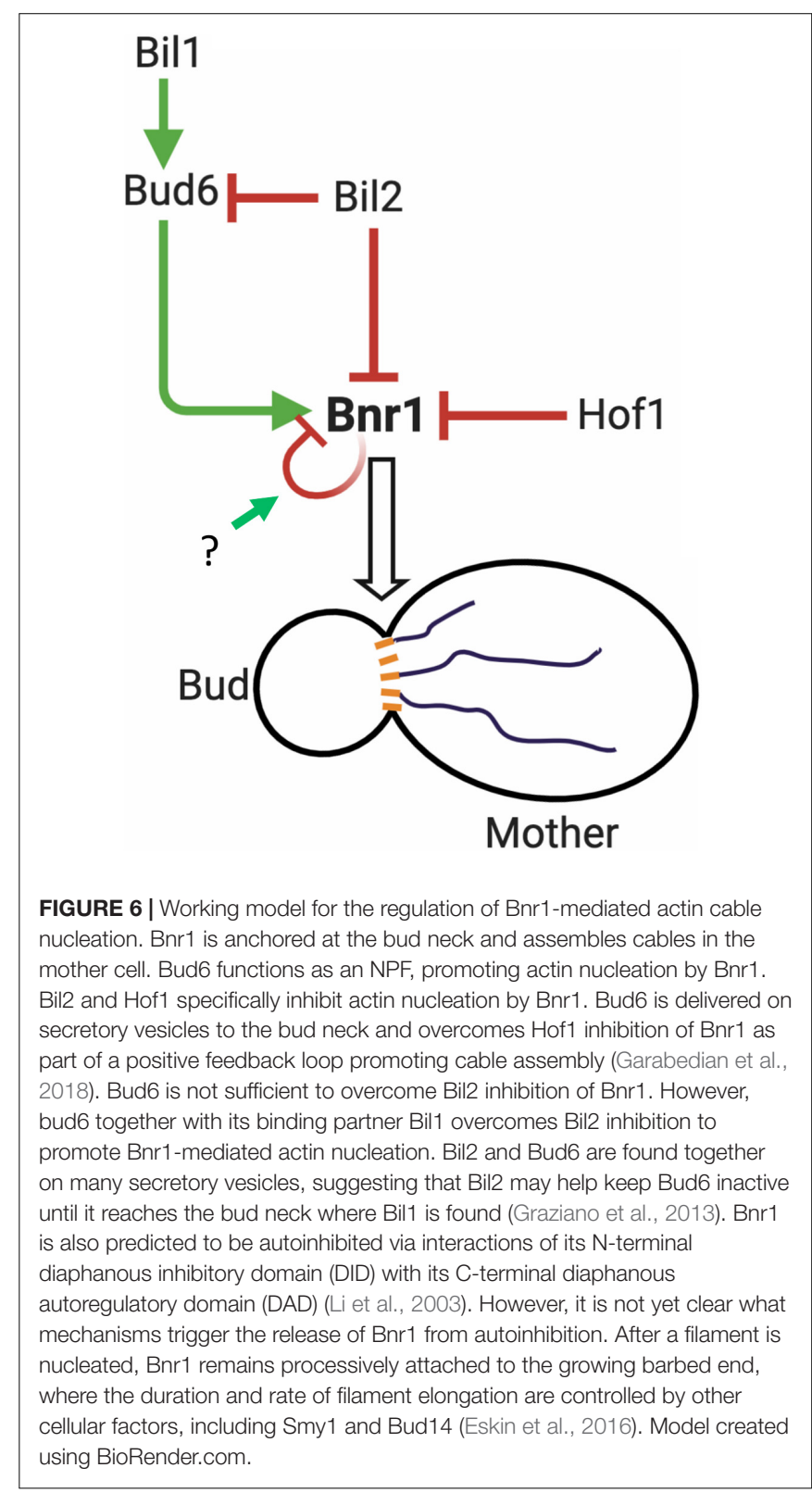


$\sim 15$-fold stronger nucleation activity compared to Bnil (Moseley and Goode, 2005). In addition, it may be significant that Bnr1 is stably tethered to the bud neck, whereas Bnil is dynamically recruited from the cytosol to the bud cortex, where it is transiently activated to nucleate cable assembly and then released (Buttery et al., 2007). These differences in the dynamics of the two formins may result in their activities requiring distinct regulatory mechanisms. Further, Bnr1 assembles cables that fill the mother cell, where cable overgrowth can be detrimental to secretory traffic. Thus, Bnr1 (but not Bnil) may require stronger inhibition to restrict its activity.

How do cells overcome Bil2 and Hof1 inhibition of Bnr1mediated actin nucleation In the case of Hof1, its inhibitory effects on Bnr1 are overcome by the formin NPF Bud6, which depends on direct binding of Bud6 to Bnr1 (Garabedian et al., 2018). In vivo, Hofl is anchored at the bud neck where Bnr1 also resides, and Bud6 is delivered on secretory vesicles to the bud neck. Genetic and biochemical evidence suggest that upon arrival Bud6 triggers Bnrl's release from Hofl inhibition to promote actin cable assembly as part of a positive feedback loop. In contrast, we found that Bud6 alone is not sufficient to overcome the inhibitory effects of Bil2 on Bnr1. Instead, this requires Bud6 and its ligand Bil1. Thus, Bill appears to be specifically required for overcoming Bil2 inhibition of Bnr1, but not Hof1 inhibition of Bnr1. Similar to Bud6, we found that Bil2 associates with secretory vesicles. Thus, Bil2 may serve to inhibit Bud6's NPF activity while on vesicles until it arrives to the bud neck, where Bill relieves inhibition. Importantly, our results do not rule out the possibility that Bil2 has additional functions (beyond directly regulating Bnr1 activity) that influence cable architecture and/or the transport of vesicles along cables. Indeed, the yeast formin inhibitor Smy1 not only directly regulates Bnr1 activity but also plays an important role in recruiting myosin to secretory vesicles in vivo, and increases myosin processivity in vitro (Hodges et al., 2009; Lwin et al., 2016). Collectively, these observations lay a foundation for understanding the in vivo regulatory circuit controlling Bnr1-mediated actin nucleation (Figure 6). However, they also raise many new questions that need to be answered in future studies, including: (i) when and where each regulatory protein interacts with Bnrl, and with each other, in vivo, (ii) whether their effects on Bnrl are regulated by post-translational modification, and (iii) what mechanism(s) trigger the release of Bnr1 from autoinhibition.

Finally, it will be important to determine if and how Bil2 (and Bil1) influence the other known cellular functions of Bud6, particularly its role in microtubule plus end capture and mitotic spindle orientation (Segal et al., 2002). Bud6 binds not only to formins but also the microtubule plus end-binding protein EB1 (Bim1), and is believed to coordinate actin and microtubule functions in vivo (Delgehyr et al., 2008; Ten Hoopen et al., 2012). Therefore, it will interesting to learn whether Bil1 and/or Bil2 contribute to this cytoskeletal crosstalk by Bud6. Further, what we learn from studying Bil1, Bil2, and Bud6 in yeast may provide valuable lessons for understanding the mechanisms coordinating actin and microtubule functions in other systems. While there are no clear homologs of Bil1, Bil2, or Bud6 outside of the fungal kingdom, mounting evidence suggests that adenomatous polyposis coli (APC) protein is a functional counterpart to Bud6 in animal cells. Similar to Bud6, APC binds to EB1 and serves as a formin NPF in vitro and in vivo (Okada et al., 2010; Breitsprecher et al., 2012; Juanes et al., 2017, 2019). Further, APC interacts with a large number of other cytoskeletal regulatory proteins. Some of these ligands may regulate APC's NPF activities in a manner related to how Bill and Bil2 regulate Bud6 NPF activity. Indeed, it was recently shown that EB1 directly inhibits the NPF activity of APC's Basic domain (Juanes et al., 2020). These findings, together with the results presented here, suggest that evolutionarily diverse organisms may have adapted to use distinct sets of proteins (lacking obvious sequence homology) to establish common regulatory schemes for controlling actin assembly.

\section{DATA AVAILABILITY STATEMENT}

The original contributions generated for this study are included in the article/Supplementary Material, further inquiries can be directed to the corresponding author.

\section{AUTHOR CONTRIBUTIONS}

TR and BG designed the research and wrote the manuscript. TR carried out all of the experiments and data analysis. BG obtained funding and supervised the project. Both authors contributed to the article and approved the submitted version.

\section{FUNDING}

This research was supported by a grant from the NIH to BG (R35 GM134895) and the Brandeis NSF Materials Research Science and Engineering Center (MRSEC) grant 142038.

\section{ACKNOWLEDGMENTS}

We are grateful to Julian Eskin, Brian Graziano, Mikael Garabedian, M. Angeles Juanes, and Alison Wirshing for useful project advice, help in generating key reagents, and/or editing of the manuscript. In addition, we thank Brianna Silverman, Malka Forman, and Yoni Israel for experimental assistance at different stages of the work.

\section{SUPPLEMENTARY MATERIAL}

The Supplementary Material for this article can be found online at: https://www.frontiersin.org/articles/10.3389/fcell.2021. 634587/full\#supplementary-material 


\section{REFERENCES}

Bi, E., and Park, H.-O. (2012). Cell polarization and cytokinesis in budding yeast. Genetics 191, 347-387. doi: 10.1534/genetics.111.132886

Breitsprecher, D., and Goode, B. L. (2013). Formins at a glance. J. Cell. Sci. 126, 1-7. doi: $10.1242 /$ jcs. 107250

Breitsprecher, D., Jaiswal, R., Bombardier, J. P., Gould, C. J., Gelles, J., Goode, B. L., et al. (2012). Rocket launcher mechanism of collaborative actin assembly defined by single-molecule imaging. Science 336, 1164-1168. doi: 10.1126/ science. 1218062

Buttery, S. M., Kono, K., Stokasimov, E., and Pellman, D. (2012). Regulation of the formin Bnrl by Septins and a MARK/Par1-family septin-associated kinase. Mol. Biol. Cell. 23, 4041-4053. doi: 10.1091/mbc.E12-05-0395

Buttery, S. M., Yoshida, S., and Pellman, D. (2007). Yeast formins Bnil and Bnr1 utilize different modes of cortical interaction during the assembly of actin cables. Mol. Biol. Cell. 18, 1826-1838. doi: 10.1091/mbc.e06-090820

Calero, M., Chen, C. Z., Zhu, W., Winand, N., Havas, K. A., Gilbert, P. M., et al. (2003). Dual prenylation is required for rab protein localization and function. Mol. Biol. Cell. 14, 1852-1867. doi: 10.1091/mbc.e02-11-0707

Chesarone, M., Gould, C. J., Moseley, J. B., and Goode, B. L. (2009). Displacement of formins from growing barbed ends by bud14 is critical for actin cable architecture and function. Dev. Cell. 16, 292-302. doi: 10.1016/j.devcel.2008.12. 001

Chesarone, M. A., DuPage, A. G., and Goode, B. L. (2010). Unleashing formins to remodel the actin and microtubule cytoskeletons. Nat. Rev. Mol. Cell. 11, 62-74. doi: $10.1038 / \mathrm{nrm} 2816$

Chesarone-Cataldo, M., Guérin, C., Yu, J. H., Wedlich-Soldner, R., Blanchoin, L., Goode, B. L., et al. (2011). The myosin passenger protein Smyl controls actin cable structure and dynamics by acting as a formin damper. Dev. Cell. 21, 217-230. doi: 10.1016/j.devcel.2011.07.004

Chhabra, E. S., and Higgs, H. N. (2007). The many faces of actin: matching assembly factors with cellular structures. Nat. Cell. Biol. 9:1110. doi: 10.1038/ ncb1007-1110

Cooper, J. A., Blum, J. D., and Pollard, T. D. (1984). Acanthamoeba castellanii capping protein: properties, mechanism of action, immunologic crossreactivity, and localization. J. Cell. Biol. 99, 217-225. doi: 10.1083/jcb.99.1. 217

Coué, M., Brenner, S. L., Spector, I., and Korn, E. D. (1987). Inhibition of actin polymerization by latrunculin A. FEBS Lett. 2, 316-318.

Delgehyr, N., Lopes, C. S., Moir, C. A., Huisman, S. M., and Segal, M. (2008). Dissecting the involvement of formins in Bud6p- mediated cortical capture of microtubules in S . Cerevisiae. J. Cell. Sci. 121, 3803-3814. doi: 10.1242/jcs. 036269

Eskin, J. A., Rankova, A., Johnston, A. B., Alioto, S. L., and Goode, B. L. (2016). Common formin-regulating sequences in Smyl and Bud14 are required for the control of actin cable assembly in vivo. Mol. Biol. Cell. 27, 828-837. doi: 10.1091/mbc.e15-09-0639

Evangelista, M., Blundell, K., Longtine, M. S., Chow, C. J., Adames, N., Pringle, J. R., et al. (1997). Bnilp, a yeast formin linking Cdc42p and the actin cytoskeleton during polarized morphogenesis. Science 276, 118-122. doi: 10.1126/science. 276.5309.118

Evangelista, M., Pruyne, D., Amberg, D. C., Boone, C., and Bretscher, A. (2002). Formins direct Arp2/3-independent actin filament assembly to polarize cell growth in yeast. Nat. Cell. Biol. 4, 260-269. doi: 10.1038/ncb770

Faix, J., and Grosse, R. (2006). Staying in shape with formins. Dev. Cell. 10, 693-706. doi: 10.1016/j.devcel.2006.05.001

Gao, L., and Bretscher, A. (2008). Analysis of unregulated formin activity reveals how yeast can balance F-actin assembly between different microfilament-based organizations. Mol. Biol. Cell. 19, 1474-1484.

Gao, L., Liu, W., and Bretscher, A. (2010). The yeast formin Bnrlp has two localization regions that show spatially and temporally distinct association with septin structures. Mol. Biol. Cell. 21, 1253-1262. doi: 10.1091/mbc.e09-10-0861

Garabedian, M. V., Stanishneva-Konovalova, T., Lou, C., Rands, T. J., Pollard, L. W., Sokolova, O. S., et al. (2018). Integrated control of formin-mediated actin assembly by a stationary inhibitor and a mobile activator. J. Cell Biol. 217, 3512-3530. doi: $10.1083 /$ jcb. 201803164
Garabedian, M. V., Wirshing, A., Vakhrusheva, A., Turegun, B., Sokolova, O. S., Goode, B. L., et al. (2020). A septin-Hof1 scaffold at the yeast bud neck binds and organizes actin cables. Mol. Biol. Cell. 31, 1988-2001. doi: 10.1091/mbc. E19-12-0693

Ghose, D., and Lew, D. (2020). Mechanistic insights into actin-driven polarity site movement in yeast. Mol. Biol. Cell. 31, 1085-1102. doi: 10.1091/mbc.E20-010040

Glomb, O., Bareis, L., and Johnsson, N. (2019). YFR016c/aip5 is part of an actin nucleation complex in yeast. Biol. Open 8, 2-10. doi: 10.1242/bio.044024

Goode, B. L., and Eck, M. J. (2007). Mechanism and function of formins in the control of actin assembly. Ann. Rev. Biochem. 76, 593-627. doi: 10.1146/ annurev.biochem.75.103004.142647

Govindan, B., Bowser, R., and Novick, P. (1995). The role of Myo2, a yeast class V myosin, in vesicular transport. J. Cell. Biol. 128, 1055-1068. doi: 10.1083/jcb. 128.6.1055

Graziano, B. R., DuPage, A. G., Michelot, A., Breitsprecher, D., Moseley, J. B., Sagot, I., et al. (2011). Mechanism and cellular function of bud6 as an actin nucleation - promoting factor. Mol. Biol. Cell. 22, 4016-4028. doi: 10.1091/mbc. E11-05-0404

Graziano, B. R., Jonasson, E. M., Pullen, J. G., Gould, C. J., and Goode, B. L. (2013). Ligand-induced activation of a formin-NPF pair leads to collaborative actin nucleation. J. Cell. Biol. 201, 595-611. doi: 10.1083/jcb.201212059

Graziano, B. R., Yu, H. Y., Alioto, S. L., Eskin, J. A., Ydenberg, C. A., Waterman, D. P., et al. (2014). The F-BAR protein Hof1 tunes formin activity to sculpt actin cables during polarized growth. Mol. Biol. Cell. 25, 1730-1743. doi: 10. 1091/mbc.E14-03-0850

Harsay, E., and Bretscher, A. (1995). Parallel secretory pathways to the cell surface in yeast. J. Cell. Biol. 131, 297-310. doi: 10.1083/jcb.131.2.297

Higgs, H. N., and Peterson, K. J. (2005). Phylogenetic analysis of the formin homology 2 domain. Mol. Biol. Cell. 16, 1-13. doi: 10.1091/mbc.E04

Higuchi, R., Vevea, J. D., Swayne, T. C., Chojnowski, R., Hill, V., Boldogh, I. R., et al. (2013). Actin dynamics affect mitochondrial quality control and aging in budding yeast. Curr. Biol. 23, 2417-2422. doi: 10.1016/j.cub.2013. 10.022

Hodges, A. R., Bookwalter, C. S., Krementsova, E. B., and Trybus, K. M. (2009). A nonprocessive class $\mathrm{V}$ myosin drives cargo processively when a kinesin- related protein is a passenger. Curr. Biol. 19, 2121-2125. doi: 10.1016/j.cub.2009.10.069

Huxley, H. E., and Brown, W. (1967). The low-angle x-ray diagram of vertebrate striated muscle and its behaviour during contraction and rigor. J. Mol. Biol. 30, 383-434. doi: 10.1016/s0022-2836(67)80046-9

Imamura, H., Tanaka, K., Hihara, T., Umikawa, M., Kamei, T., Takahashi, K., et al. (1997). Bnilp and Bnrlp: downstream targets of the rho family small G-proteins which interact with profilin and regulate actin cytoskeleton in saccharomyces cerevisiae. EMBO J. 16, 2745-2755.

Ito, T., Chiba, T., Ozawa, R., Yoshida, M., Hattori, M., and Sakaki, Y. (2001). A Comprehensive Two-Hybrid analysis to explore the yeast protein interactome. Proc. Natl. Acad. Sci. U S A. 98, 4569-4574.

Jaiswal, R., Breitsprecher, D., Collins, A., Corrêa, I. R. Jr., Xu, M. Q., and Goode, B. L. (2013). The formin daam 1 and fascin directly collaborate to promote filopodia formation. Curr. Biol. 23, 1373-1379. doi: 10.1016/j.cub.2013.06.013

Jin, H., and Amberg, D. C. (2000). The secretory pathway mediates localization of the cell polarity regulator Aip3p/Bud6p. Mol. Biol. Cell. 11, 647-661. doi: 10.1091/mbc.11.2.647

Juanes, M. A., Bouguenina, H., Eskin, J. A., Jaiswal, R., Badache, A., Goode, B. L. et al. (2017). Adenomatous polyposis coli nucleates actin assembly to drive cell migration and microtubule-induced focal adhesion turnover. J. Cell. Biol. 216, 2859-2875. doi: 10.1083/jcb.201702007

Juanes, M. A., Fees, C. P., Hoeprich, G. J., Jaiswal, R., and Goode, B. L. (2020). EB1 Directly regulates APC-mediated actin nucleation. Curr. Biol. 30, 4763-4772.

Juanes, M. A., Isnardon, D., Badache, A., Brasselet, S., Mavrakis, M., Goode, B. L. et al. (2019). The role of APC-mediated actin assembly in microtubule capture and focal adhesion turnover. J. Cell. Biol. 218, 3415-3435. doi: 10.1083/jcb. 201904165

Kamei, T., Tanaka, K., Hihara, T., Umikawa, M., Imamura, H., Kikyo, M., et al. (1998). Interaction of Bnrlp with a novel Src homology 3 domain-containing Hoflp: implication in cytokinesis in saccharomyces cerevisiae. J. Biol. Chem. 273, 28341-28345. doi: 10.1074/jbc.273.43.28341 
Kono, K., Saeki, Y., Yoshida, S., Tanaka, K., and Pellman, D. (2012). Proteasomal degradation resolves competition between cell polarization and cellular wound healing. Cell 150, 151-164. doi: 10.1016/j.cell.2012.05.030

Kovar, D. R. (2006). Molecular details of formin-mediated actin assembly. Curr. Opin. Cell. Biol. 18, 11-17. doi: 10.1016/J.CEB.2005.12.011

Li, F., Henry, N., and Higgs. (2003). The mouse formin MDial is a potent actin nucleation factor regulated by autoinhibition. Curr. Biol. 13, 1335-1340.

Longtine, M. S., McKenzie, A., Demarini, D. J., Shah, N. G., Wach, A., Brachat, A., et al. (1998). Additional modules for versatile and economical PCR-based gene deletion and modification in saccharomyces cerevisiae. Yeast 961, 953-961.

Lwin, K. M., Li, D., and Bretscher, A. (2016). Kinesin-related Smy1 enhances the Rab-dependent association of myosin-V with secretory cargo. Mol. Biol. Cell. 27, 2450-2462. doi: 10.1091/mbc.E16-03-0185

Moseley, B., and Goode, B. L. (2006). The yeast actin cytoskeleton: from cellular function to biochemical mechanism. Microbiol. Mol. Biol. Rev. 70, 605-645. doi: 10.1128/MMBR.00013-06

Moseley, J. B., and Goode, B. L. (2005). Differential activities and regulation of saccharomyces cerevisiae formin proteins Bnil and Bnr1 by Bud6. J. Biol. Chem. 280, 28023-28033. doi: 10.1074/jbc.M503094200

Moseley, J. B., Sagot, I., Manning, A. L., Xu, Y., Eck, M. J., Pellman, D., et al. (2004). A conserved mechanism for Bnil- and MDial-induced actin assembly and dual regulation of Bnil by Bud6 and Profilin. Mol. Biol. Cell. 15, 896-907. doi: $10.1091 / \mathrm{mbc}$. 03-08-0621

Mu, A., Fung, T. S., Kettenbach, A. N., Chakrabarti, R., and Higgs, H. N. (2019). A complex containing lysine-acetylated actin inhibits the formin INF2. Nat. Cell Biol. 21, 592-602. doi: 10.1038/s41556-019-0307-4

Okada, K., Bartolini, F., Deaconescu, A. M., Moseley, J. B., Dogic, Z., Grigorieff, N., et al. (2010). Adenomatous polyposis coli protein nucleates actin assembly and synergizes with the formin MDia1. J. Cell. Biol. 189, 1087-1096. doi: 10.1083/ jcb.201001016

Okada, K., Ravi, H., Smith, E. M., and Goode, B. L. (2006). Aip1 and pofilin promote rapid turnover of yeast actin patches and cables: a coordinated mechanism for severing and capping filaments. Mol. Biol. Cell. 17, 2855-2868. doi: 10.1091/mbc.e06-02-0135

Ozaki-Kuroda, K., Yamamoto, Y., Nohara, H., Kinoshita, M., Fujiwara, T., Irie, K., et al. (2001). Dynamic localization and function of Bnilp at the sites of directed growth in saccharomyces cerevisiae. Mol. Cell. Biol. 21, 827-839. doi: 10.1128/MCB.21.3.827-839.2001

Proszynski, T. J., Klemm, R. W., Gravert, M., Hsu, P. P., Gloor, Y., Wagner, J., et al. (2005). A genome-wide visual screen reveals a role for sphingolipids and ergosterol in cell surface delivery in yeast. Proc. Natl. Acad. Sci. U S A. 102, 17981-17986.

Pruyne, D., Gao, L., Bi, E., and Bretscher, A. (2004). Stable and dynamic axes of polarity use distinct formin isoforms in budding yeast. Mol. Biol. Cell 15, 4971-4989. doi: 10.1091/mbc.e04-04-0296

Pruyne, D. W., Schott, D. H., and Bretscher, A. (1998). Tropomyosin-containing actin cables direct the Myo2p-dependent polarized delivery of secretory vesicles in budding yeast. J. Cell Biol. 143, 1931-1945. doi: 10.1083/jcb.143.7.1931

Sagot, I., Klee, S. K., and Pellman, D. (2002a). Yeast formins regulate cell polarity by controlling the assembly of actin cables. Nat. Cell Biol. 4, 42-50. doi: 10.1038/ ncb719
Sagot, I., Rodal, A. A., Moseley, J., Goode, B. L., and Pellman, D. (2002b). An actin nucleation mechanism mediated by Bnil and profilin. Nat. Cell Biol. 4, 626-631. doi: $10.1038 /$ ncb834

Segal, M., Bloom, K., and Reed, S. I. (2000). Bud6 directs sequential microtubule interactions with the bud tip and bud neck during spindle morphogenesis in saccharomyces cerevisiae. Mol. Biol. Cell. 11, 36893702 .

Segal, M., Bloom, K., and Reed, S. I. (2002). Kar9p-independent microtubule capture at Bud6p cortical sites primes spindle polarity before bud emergence in saccharomyces cerevisiae. Mol. Biol. Cell 13, 41414155.

Slubowski, C. J., Funk, A. D., Roesner, J. M., Paulissen, S. M., and Huang, L. S. (2015). Plasmids for C-terminal tagging in saccharomyces cerevisiae that contain improved GFP proteins, Envy and Ivy. Yeast 32, 379-387. doi: 10.1002/ yea.3065

Spudich, J. A., and Watt, S. (1971). The regulation of rabbit skeletal muscle contraction. I. biochemical studies of the interaction of the tropomyosintroponin complex with actin and the proteolytic fragments of myosin. J. Biol. Chem. 246, 4866-4871.

Ten Hoopen, R., Cepeda-García, C., Fernández-Arruti, R., Juanes, M. A., Delgehyr, N., Segal, M., et al. (2012). Mechanism for astral microtubule capture by cortical bud6p priming spindle polarity in S. Cerevisiae. Curr. Biol. 22, 1075-1083. doi: 10.1016/j.cub.2012.04.059

Vallen, E. A., Caviston, J., and Bi, E. (2000). Roles of Hof1p, Bnilp, Bnrlp, and Myolp in cytokinesis in saccharomyces cerevisiae. Mol. Biol. Cell. 11, 593-611. doi: $10.1091 / \mathrm{mbc} .11 .2 .593$

Xie, Y., Sun, J., Han, X., Turšić-Wunder, A., Toh, J. D. W., Hong, W., et al. (2019). Polarisome scaffolder Spa2-mediated macromolecular condensation of Aip5 for actin polymerization. Nat. Commun. 10, 1-18.

Xu, T., Vavylonis, D., Tsai, F. C., Koenderink, G. H., Nie, W., Yusuf, E., et al. (2015). SOAX: a software for quantification of 3D biopolymer networks. Sci. Rep. 5:9081. doi: 10.1038/srep09081

Yang, H.-C., and Pon, L. A. (2002). Actin cable dynamics in budding yeast. Proc. Natl. Acad. Sci. 99, 751-756. doi: 10.1073/pnas.022462899

Yu, H., Braun, P., Yildirim, M. A., Lemmens, I., Venkatesan, K., Sahalie, J., et al. (2008). High-quality binary protein interaction map of the yeast interactome network. Science 322, 104-110.

Yu, J. H., Crevenna, A. H., Bettenbühl, M., Freisinger, T., and Wedlich-Söldner, R. (2011). Cortical actin dynamics driven by formins and myosin V. J. Cell. Sci. 124, 1533-1541. doi: 10.1242/jcs.079038

Conflict of Interest: The authors declare that the research was conducted in the absence of any commercial or financial relationships that could be construed as a potential conflict of interest.

Copyright (c) 2021 Rands and Goode. This is an open-access article distributed under the terms of the Creative Commons Attribution License (CC BY). The use, distribution or reproduction in other forums is permitted, provided the original author(s) and the copyright owner(s) are credited and that the original publication in this journal is cited, in accordance with accepted academic practice. No use, distribution or reproduction is permitted which does not comply with these terms. 